\title{
Review of Cranked-Arrow Wing Aerodynamics Project: Its International Aeronautical Community Role
}

\author{
John E. Lamar ${ }^{*}$ and Clifford J. Obara ${ }^{\dagger}$ \\ NASA Langley Research Center, Hampton, VA 23681-2199
}

This paper provides a brief history of the F-16XL-1 aircraft, its role in the High Speed Research (HSR) program and how it was morphed into the Cranked Arrow Wing Aerodynamics Project (CAWAP). Various flight, wind-tunnel and Computational Fluid Dynamics (CFD) data sets were generated during the CAWAP. These unique and open flight datasets for surface pressures, boundary-layer profiles and skinfriction distributions, along with surface flow data, are described and sample data comparisons given. This is followed by a description of how the project became internationalized to be known as Cranked Arrow Wing Aerodynamics Project International (CAWAPI) and is concluded by an introduction to the results of a 4 year CFD predictive study of data collected at flight conditions by participating researchers.

\section{Nomenclature}

\begin{tabular}{|c|c|}
\hline AVT & Applied Vehicle Technology (one of seven technical panels within the RTO) \\
\hline BART & Basic Aerodynamic Research Tunnel \\
\hline BL & butt line on airplane, in., positive on right wing (See fig. 2) \\
\hline CAWAP & Cranked Arrow Wing Aerodynamics Project \\
\hline CAWAPI & Cranked Arrow Wing Aerodynamics Project International \\
\hline CFD & Computational Fluid Dynamics \\
\hline $\mathrm{C}_{\mathrm{p}}$ & static-pressure coefficient \\
\hline $\mathrm{c}_{\mathrm{f}}$ & local skin friction coefficient \\
\hline EFD & Experimental Fluid Dynamics \\
\hline ESP & Electronic Scanning Pressure \\
\hline ET & Exploratory Team \\
\hline $\mathrm{FC}$ & Flight Condition \\
\hline FS & fuselage station on airplane, in., positive aft (See fig. 2) \\
\hline F-16XL-1 & $\begin{array}{l}\text { An extensively modified version of the single-seat F-16A aircraft which is longer and has a } \\
\text { cranked arrow wing instead of a trapezoidal wing with leading-edge strake }\end{array}$ \\
\hline HUD & heads-up display \\
\hline HSR & High Speed Research \\
\hline HSCT & High Speed Civil Transport \\
\hline $\mathrm{h}$ & airplane altitude, $\mathrm{ft}$ \\
\hline ITAR & International Traffic in Arms Regulations \\
\hline iges & Initial Graphics Exchange Specifications $->$ geometry descriptor \\
\hline$i, j, k$ & grid indices \\
\hline LaRC & Langley Research Center \\
\hline LE & leading edge \\
\hline $\mathrm{M}_{\infty}$ & free-stream Mach number \\
\hline NASA & National Aeronautics and Space Administration \\
\hline NATO & North Atlantic Treaty Organization \\
\hline PSF & $\begin{array}{l}\text { Performance, Stability \& Control and Fluid Physics - one of the standing Technical } \\
\text { Committees of the AVT Panel }\end{array}$ \\
\hline PSP & Pressure Sensitive Paint \\
\hline RTB & Research and Technology Board \\
\hline RTO & Research and Technology Organization - scientific arm of NATO \\
\hline
\end{tabular}

\footnotetext{
* CAWAP Principal Investigator, Configuration Aerodynamics Branch, MS 499, Associate Fellow AIAA

${ }^{\dagger}$ CAWAP Project Engineer, Experimental Research Services, MS 237, Member AIAA
} 


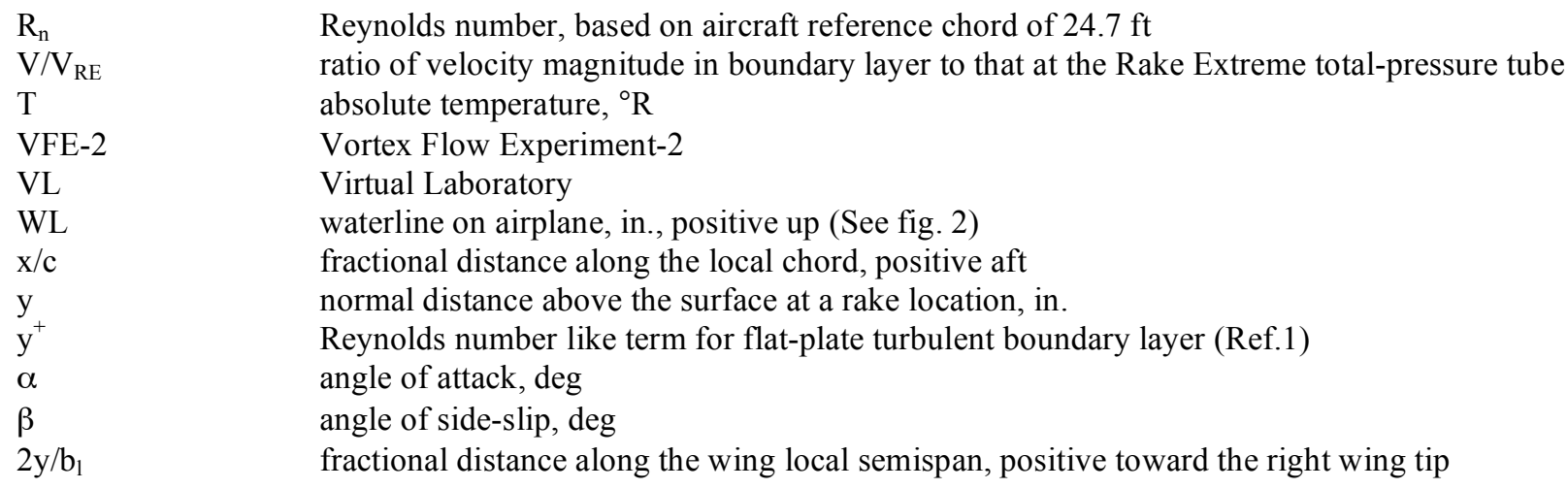

Subscripts

avg average value

nom nominal value

\section{Introduction}

This paper provides a brief history of the F-16XL-1 aircraft, its role in the High Speed Research (HSR) program and how it was morphed into the Cranked Arrow Wing Aerodynamics Project (CAWAP). Various flight, wind-tunnel and Computational Fluid Dynamics (CFD) data sets were generated during the CAWAP ${ }^{2}$. These are described and sample data comparisons given. This is followed by a description of how the project became internationalized and is concluded by an introduction to the results of a 4 year CFD predictive study of data collected at flight conditions.

\section{A. F-16XL airplane}

\section{CAWAP history}

The F-16XL-1 airplane is a single-place, fighter-type prototype aircraft developed by the General Dynamics Corporation-Ft.Worth Division (now Lockheed Martin Tactical Aircraft Systems) by stretching the fuselage of a Full-Scale Development F-16A and adding a cranked-arrow wing, a modified fuel system, and a modified flight control system. There were two F-16XL aircraft built, the -1 , which was used in the CAWAP, and a two-place version, the -2 . Consequently, the terms F-16XL and F-16XL-1 are used interchangeably in this paper. Both aircraft had scheduled leading-edge flaps, elevons, and ailerons on the wing for control. The technical specifications for the airplane are given in Table 1, which is reconstructed from reference 1. Details on the construction of the aircraft and its intended missions are given in references 3-5.

Table 1. - F-16XL-1 Airplane Specifications

\begin{tabular}{|c|c|}
\hline Feature & Value \\
\hline Wing Span & $32.4 \mathrm{ft}$ \\
\hline Height & $17.606 \mathrm{ft}$ \\
\hline Length & $54.155 \mathrm{ft}$ \\
\hline Reference Chord & $24.7 \mathrm{ft}$ \\
\hline Theoretical Root Chord & $41.75 \mathrm{ft}$ \\
\hline Wing Area & $646.37 \mathrm{ft}^{2}$ \\
\hline Reference Wing Area & $600 \mathrm{ft}^{2}$ \\
\hline Reference Aspect Ratio & 1.75 \\
\hline Typical Takeoff Weight & $35,000 \mathrm{lb}$ \\
\hline Engine; Max Thrust & Pratt \& Whitney F100-PW-200;23,830 lb \\
\hline
\end{tabular}


The design of the cranked-arrow wing was a cooperative effort of the NASA Langley Research Center and the General Dynamics Corporation. The new wing, common for both the -1 and -2 versions, was designed to provide the F-16 aircraft with improved supersonic performance while maintaining comparable transonic performance to that provided by the current F-16 design. As shown in figure 1, the resultant design had a leadingedge (LE) sweep angle of $70^{\circ}$ inboard and $50^{\circ}$ outboard of the crank. At the juncture of the wing leading edge with the fuselage, an "S-blend curve" was placed in the leading edge to alleviate a pitch instability that was found to occur at high angles of attack in wind-tunnel tests. All flight test data reported in reference 1were collected with the air dams - upper-surface fences mounted near the wing leading-edge crank - and wing-tip missiles installed, as shown in figures 1 and 2 .

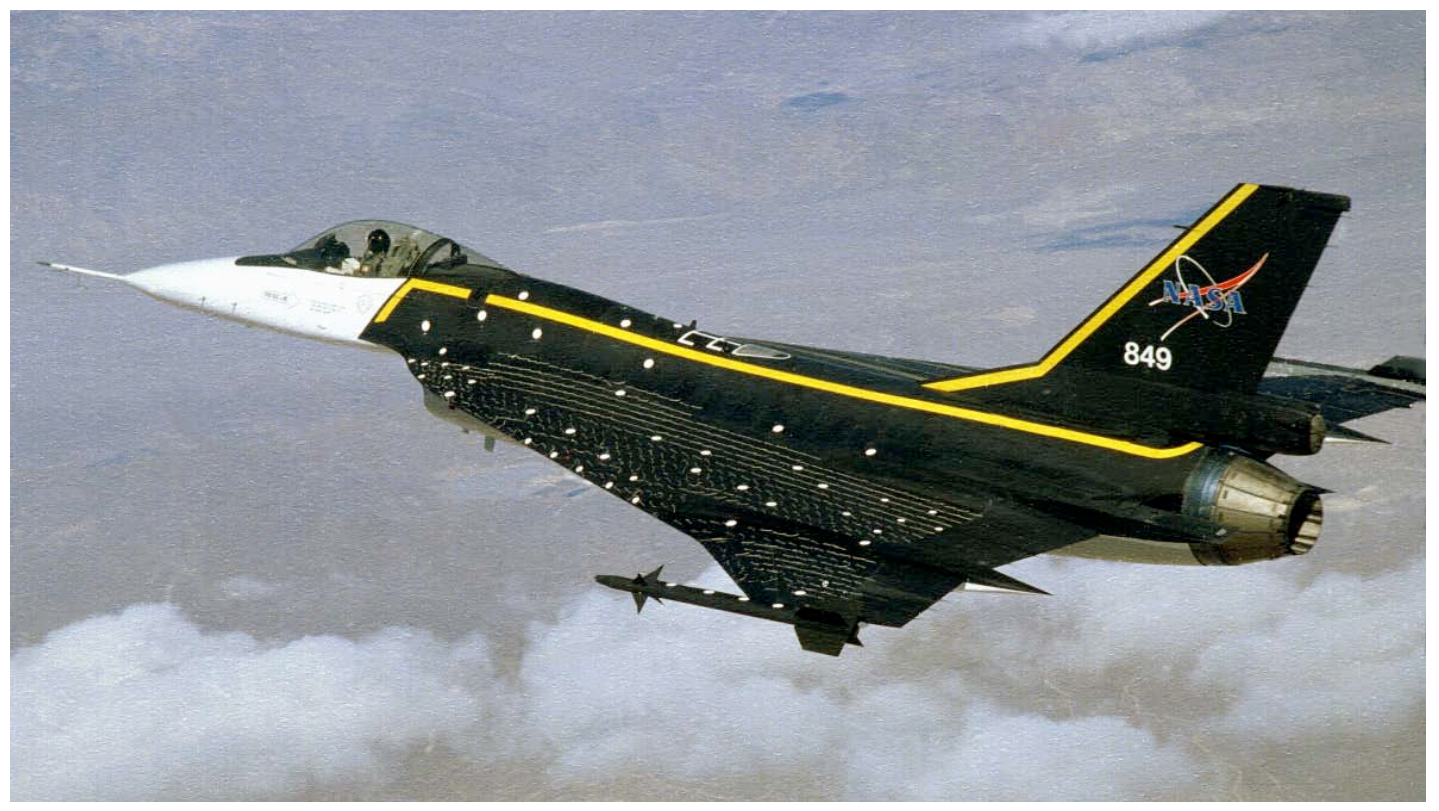

Figure 1. F-16XL-1 aircraft with missiles, tufts, modified flow-visualization paint scheme, and video targets at NASA Dryden Flight Research Center (NASA Photo EC96-43508-2). 


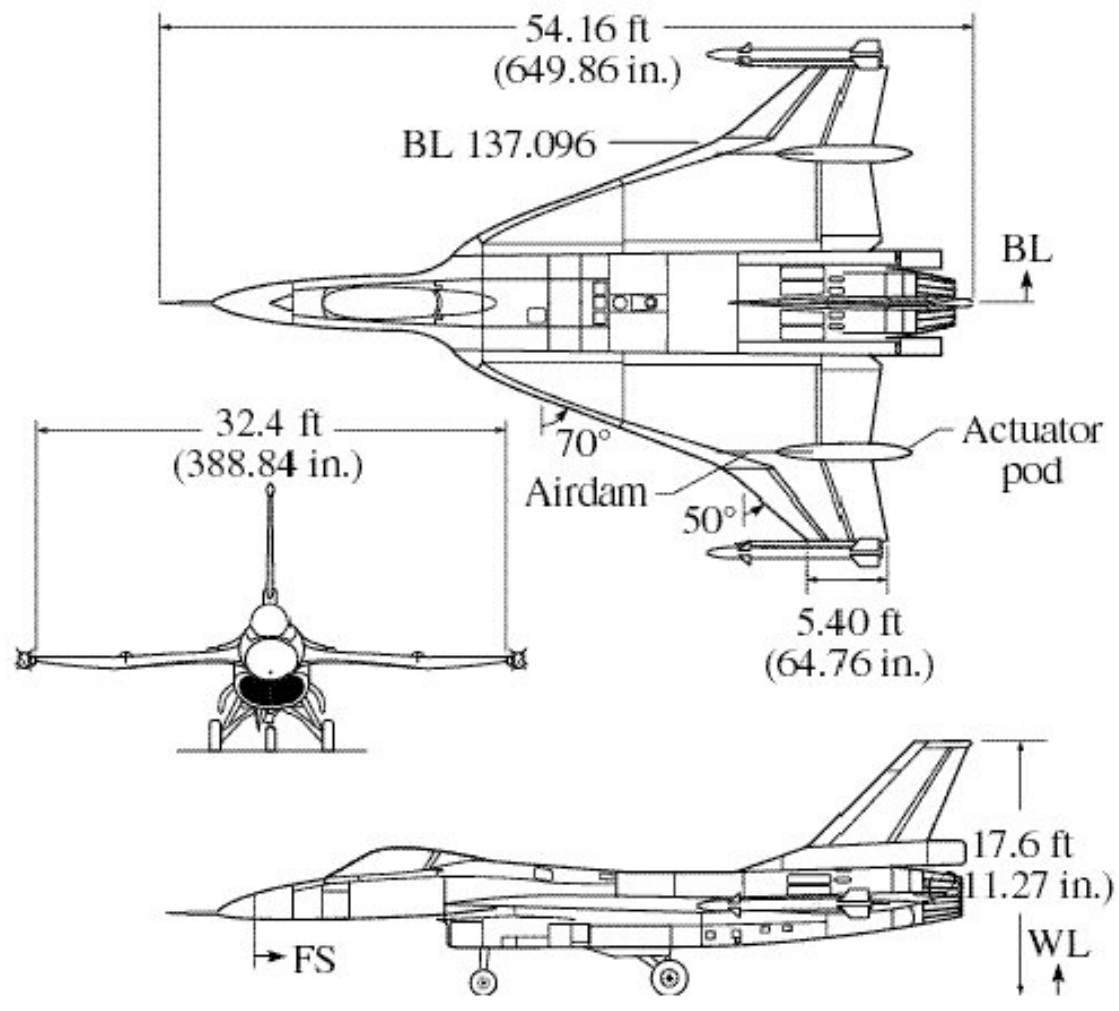

Figure 2. Three-view drawing of F-16XL-1 airplane. Linear dimensions are in feet (inches).

\section{B. HSR program overview}

This program was started in 1990 to develop the technologies that would result in a supersonic passenger jet that would fly 300 passengers at more than twice the speed of sound while maintaining comparable ticket prices to current subsonic transports. As envisioned by the government and industrial partners, the high speed civil transport (HSCT) would cross the Atlantic or Pacific oceans in half the time of modern subsonic jets using new technologies for airframe manufacturing, propulsion systems, aerodynamics, and reduced environmental impacts. By 1995, based on several industry design concepts, computer modeling, and wind tunnel tests, a Technology Concept Airplane was selected as a common reference point in furthering the technology development process. This single concept would have improved aerodynamic performance and operational characteristics while also meeting environmental goals for emissions and noise pollution. The HSCT concept is depicted in Fig. 3.

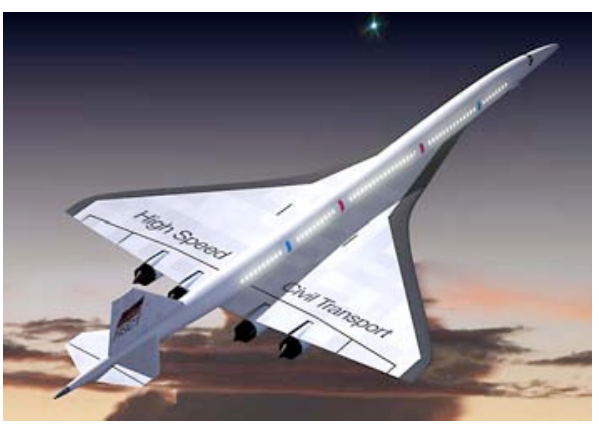

Figure 3. High-Speed Civil Transport concept. 
Due to economic constraints, the program was phased out in fiscal year 1999. Despite the cancellation, the program still managed to meet or exceed many of the original HSR program goals. New high-temperature composite materials and structural concepts were developed to keep weight and manufacturing costs down while maintaining the strength and durability that would be required for the aircraft. NASA engineers developed new vision systems for the pilots that maintained safety and performance capabilities while eliminating the need for a drooped nose similar to the Concorde. Another critical element to the program was the development of a propulsion system that would not harm the environment both in atmospheric effects as well as mitigating the noise, while providing the performance and durability required to keep the aircraft economically viable.

\section{F-16XL flight overview / planning for HSR}

Early in the development of the HSR program, it was determined that improved aerodynamic performance, while reducing the noise at high-lift conditions during take-off and landing, was a critical element to the program. The availability of the F-16XL aircraft with its cranked wing configuration, which was similar to the HSCT concept, provided a unique opportunity for CFD correlation and code validation with flight and wind-tunnel data. The project was divided into three phases based on the required geometry changes to the basic aircraft. The phases are depicted schematically in Fig. 4 relative to the aircraft modification required. Phase 1 was the basic airplane with no modifications. This phase would serve as a baseline for the future modifications. Phase 2 required the removal of the "S" curve in the apex region of the wing. This second configuration was more representative of the HSCT cranked wing. The third and final phase would incorporate a high-lift device along the entire leading edge of the aircraft. The exact configuration of the high-lift device would be determined from wind-tunnel experiments and CFD predictions. The high-lift configuration would be representative of the HSCT in a take-off or landing configuration.

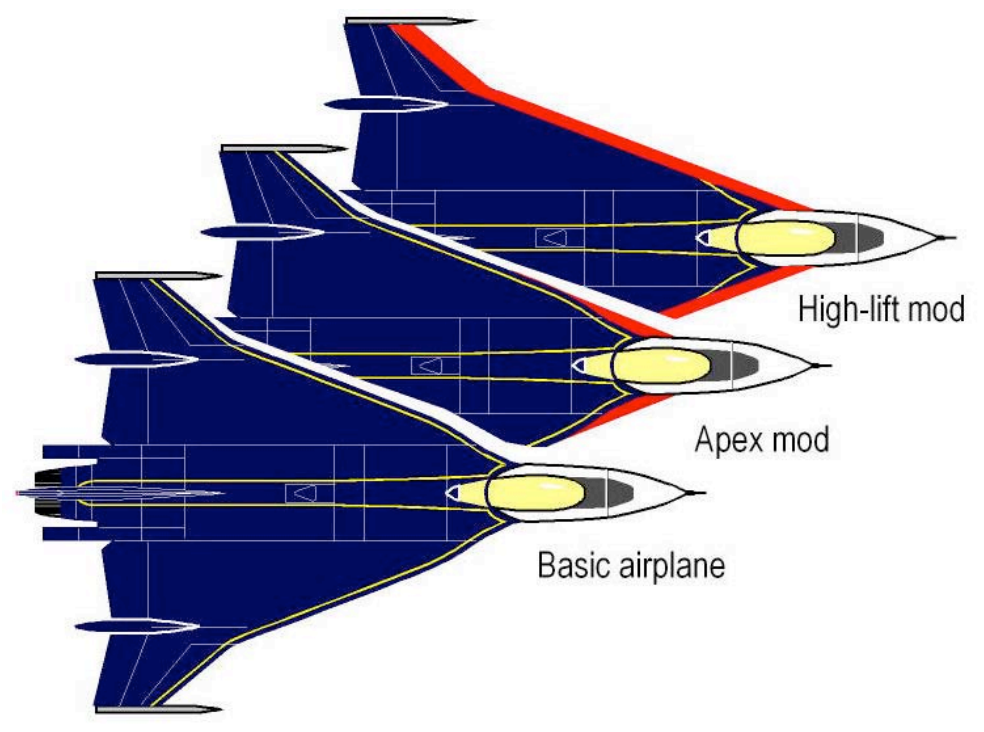

Figure 4. F-16XL-1 research aircraft modifications.

The primary objective of the flight test project was to verify the performance of high-lift concepts while ensuring compliance with community noise standards. The first step was to establish a ground to flight correlation for the cranked-arrow wing planform. All three configurations as described would be flight-tested and the data would be used as a calibration of the design analysis tools as well as the noise prediction codes. In addition, advanced operating procedures for take-off and landing would be evaluated. The final objective was to assess integration and "real-world" operation of high-lift devices. A schematic of the ground to flight correlation is shown in Fig. 5. 


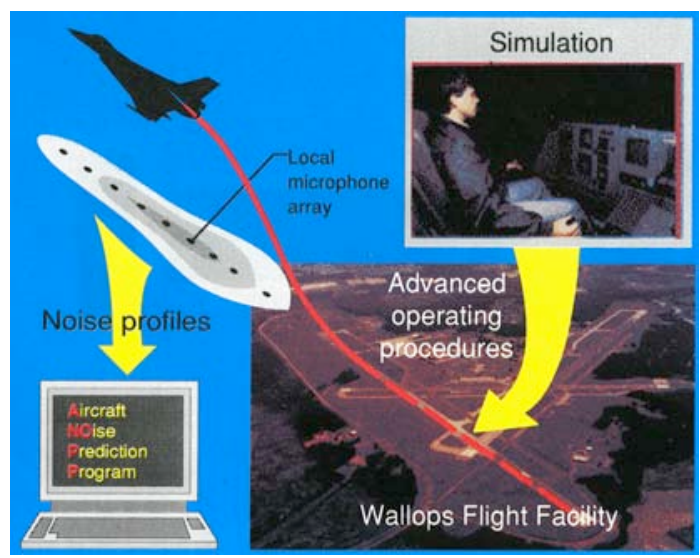

Figure 5. Schematic of ground to flight correlation for assessing the impact of aerodynamic and operational concepts on noise profiles.

\section{CAWAP}

During the Phase 1 experiments on the baseline F-16XL aircraft in the spring of 1994, the remainder of the project as planned was cancelled due to funding limitations. Sufficient funding was provided to complete the first phase of the project, with a slight change to the objectives. This was the start of the CAWAP as it is known today. The revised objectives were to document upper-surface flow physics at high-lift and transonic test conditions and to characterize the stability and control of the aircraft. The original intent of a flight, wind-tunnel, and CFD correlation experiment would be maintained, albeit for the baseline F-16XL configuration only. Table 2 illustrates the extensive set of planned comparisons between flight, wind-tunnel and CFD, and Table 3 provides the actual set of comparisons made. (These two tables are reconstructed and modified from Ref. 2.)

Table 2. Planned F-16XL CAWAP Data Comparisons

\begin{tabular}{|c|l|l|l|}
\hline Item & Data comparison & Data type & Data source \\
\hline 1 & On and off surface flow & $\begin{array}{l}\text { Tufts } \\
\text { Static pressures in a row } \\
\text { Vapor screen } \\
\text { Particle traces }\end{array}$ & $\begin{array}{l}\text { Flight } \\
\text { Flight } \\
\text { Flight } \\
\text { CFD }\end{array}$ \\
\hline 2 & Surface flow and pressure & $\begin{array}{l}\text { Oil flow } \\
\text { Pressure sensitive paint (PSP) }\end{array}$ & $\begin{array}{l}\text { Wind tunnel } \\
\text { Wind tunnel }\end{array}$ \\
\hline 3 & Surface pressure & $\begin{array}{l}\text { Pressure sensitive paint } \\
\text { Calculations }\end{array}$ & $\begin{array}{l}\text { Wind tunnel } \\
\text { CFD }\end{array}$ \\
\hline 4 & Vortex core location & $\begin{array}{l}\text { Vapor screen } \\
\text { Particle traces }\end{array}$ & $\begin{array}{l}\text { Wind tunnel } \\
\text { CFD }\end{array}$ \\
\hline 5 & Vortex core location & $\begin{array}{l}\text { Vapor screen } \\
\text { Particle traces }\end{array}$ & $\begin{array}{l}\text { Flight, wind tunnel } \\
\text { CFD }\end{array}$ \\
\hline 6 & Surface flow & $\begin{array}{l}\text { Oil flow } \\
\text { Tufts } \\
\text { Liquid Crystals }\end{array}$ & $\begin{array}{l}\text { Flight } \\
\text { Flight } \\
\text { Flight }\end{array}$ \\
\hline 7 & Surface flow & $\begin{array}{l}\text { Oil flow } \\
\text { Tufts } \\
\text { Particle traces }\end{array}$ & $\begin{array}{l}\text { Flight } \\
\text { Flight } \\
\text { CFD }\end{array}$ \\
\hline 8 & Surface flow & $\begin{array}{l}\text { Oil flow } \\
\text { Particle traces }\end{array}$ & $\begin{array}{l}\text { Flight, wind tunnel } \\
\text { CFD }\end{array}$ \\
\hline 9 & Surface pressure & $\begin{array}{l}\text { Pressure sensitive paint } \\
\text { Particle traces }\end{array}$ & $\begin{array}{l}\text { Wind tunnel } \\
\text { Wind tunnel }\end{array}$ \\
\hline \multirow{2}{*}{10} & Off surface flow & $\begin{array}{l}\text { Vapor screen } \\
\text { Five-hole probe }\end{array}$ & $\begin{array}{l}\text { Flight, wind tunnel } \\
\text { Wind tunnel }\end{array}$ \\
\hline
\end{tabular}

6

American Institute of Aeronautics and Astronautics 
Table 2. Concluded.

\begin{tabular}{|c|c|c|c|}
\hline Item & Data comparison & Data type & Data source \\
\hline 11 & On and off surface flow & $\begin{array}{l}\text { Oil flow } \\
\text { Vapor screen } \\
\text { Particle traces }\end{array}$ & $\begin{array}{l}\text { Flight } \\
\text { Flight } \\
\text { CFD }\end{array}$ \\
\hline 12 & On and off surface flow & $\begin{array}{l}\text { Oil flow } \\
\text { Vapor screen } \\
\text { Five-hole probe }\end{array}$ & $\begin{array}{l}\text { Flight, wind tunnel } \\
\text { Flight, wind tunnel } \\
\text { Wind tunnel }\end{array}$ \\
\hline 13 & Surface flow & $\begin{array}{l}\text { Oil flow } \\
\text { Tufts } \\
\text { Liquid Crystals } \\
\text { Propylene-glycol-methyl-ether traces }\end{array}$ & $\begin{array}{l}\text { Flight } \\
\text { Flight } \\
\text { Flight } \\
\text { Flight }\end{array}$ \\
\hline 14 & Surface flow & $\begin{array}{l}\text { Oil flow } \\
\text { Tufts } \\
\text { Particle traces } \\
\text { Propylene-glycol-methyl-ether traces }\end{array}$ & $\begin{array}{l}\text { Flight } \\
\text { CFD } \\
\text { Flight } \\
\text { Flight }\end{array}$ \\
\hline 15 & Vortex core location & $\begin{array}{l}\text { Vapor screen } \\
\text { Dye traces } \\
\text { Particle traces }\end{array}$ & $\begin{array}{l}\text { Wind tunnel } \\
\text { Water tunnel } \\
\text { CFD }\end{array}$ \\
\hline 16 & Surface pressure contours & $\begin{array}{l}\text { Static pressures } \\
\text { Calculations }\end{array}$ & $\begin{array}{l}\text { Flight, wind tunnel } \\
\text { CFD }\end{array}$ \\
\hline 17 & Surface pressure & $\begin{array}{l}\text { Pressure sensitive paint } \\
\text { Static pressure in a row }\end{array}$ & $\begin{array}{l}\text { Flight } \\
\text { Flight, wind tunnel }\end{array}$ \\
\hline 18 & Surface pressure & $\begin{array}{l}\text { Pressure sensitive paint } \\
\text { Static pressures in a row } \\
\text { Static-pressure surface }\end{array}$ & $\begin{array}{l}\text { Flight } \\
\text { Flight, CFD } \\
\text { CFD }\end{array}$ \\
\hline 19 & $\begin{array}{l}\text { On and off surface flow } \\
\text { contours }\end{array}$ & $\begin{array}{l}\text { Tufts } \\
\text { Particle traces } \\
\text { Stagnation pressure }\end{array}$ & $\begin{array}{l}\text { Flight } \\
\text { CFD } \\
\text { CFD }\end{array}$ \\
\hline 20 & Boundary-layer profile & $\begin{array}{l}\text { Rake } \\
\text { Velocities }\end{array}$ & $\begin{array}{l}\text { Flight } \\
\text { CFD }\end{array}$ \\
\hline 21 & Skin-friction distribution & $\begin{array}{l}\text { Modified Preston tube } \\
\text { Equation }\end{array}$ & $\begin{array}{l}\text { Flight } \\
\text { CFD }\end{array}$ \\
\hline 22 & Leading-edge boundary layer & Hot-film gauges & Flight \\
\hline
\end{tabular}

Table 3. Actual F-16XL CAWAP Data Comparisons

\begin{tabular}{|c|l|l|l|}
\hline Item* & Data comparison & Data type & Data source \\
\hline 3 & Surface pressure contours & $\begin{array}{l}\text { Pressure sensitive paint } \\
\text { Calculations }\end{array}$ & $\begin{array}{l}\text { Wind tunnel } \\
\text { CFD }\end{array}$ \\
\hline 6 & Surface flow & $\begin{array}{l}\text { Oil flow } \\
\text { Tufts } \\
\text { Liquid Crystals }\end{array}$ & $\begin{array}{l}\text { Flight } \\
\text { Flight } \\
\text { Flight }\end{array}$ \\
\hline $12 \mathrm{a}$ & On and off surface flow & $\begin{array}{l}\text { Oil flow } \\
\text { Vapor screen }\end{array}$ & $\begin{array}{l}\text { Wind tunnel } \\
\text { Wind tunnel }\end{array}$ \\
\hline $16 \mathrm{a}$ & Surface pressure contours & $\begin{array}{l}\text { Static pressures } \\
\text { Calculations }\end{array}$ & $\begin{array}{l}\text { Flight } \\
\text { CFD }\end{array}$ \\
\hline $17 \mathrm{a}$ & Surface pressure & Static pressure in a row & Flight, wind tunnel \\
\hline $18 \mathrm{a}$ & Surface pressure & $\begin{array}{l}\text { Static pressures in a row } \\
\text { Static-pressure surface }\end{array}$ & $\begin{array}{l}\text { Flight, CFD } \\
\text { CFD }\end{array}$ \\
\hline 19 & On and off surface flow & $\begin{array}{l}\text { Tufts } \\
\text { Particle traces } \\
\text { Stagnation pressure contours }\end{array}$ & $\begin{array}{l}\text { Flight } \\
\text { CFD } \\
\text { CFD }\end{array}$ \\
\hline
\end{tabular}


Table 3. Concluded.

\begin{tabular}{|c|l|l|l|}
\hline Item* & Data comparison & Data type & Data source \\
\hline 20 & Boundary-layer profile & $\begin{array}{l}\text { Rake } \\
\text { Velocities }\end{array}$ & $\begin{array}{l}\text { Flight } \\
\text { CFD }\end{array}$ \\
\hline 21 & Skin-friction distribution & $\begin{array}{l}\text { Modified Preston tube } \\
\text { Equation }\end{array}$ & $\begin{array}{l}\text { Flight } \\
\text { CFD }\end{array}$ \\
\hline 22 & Leading-edge boundary layer & Hot-film gauges & Flight \\
\hline
\end{tabular}

*The "a" in the item number signifies a reduction in the actual number of items being compared versus the planned number.

Note that in Table 2 an attempt was to be made to perform off-surface laser-vapor-screen data using seeded material, and to develop surface streaklines using propylene-glycol-methyl-ether. However, these two types of data were not obtained due to the lack of funding and higher priority datasets that needed to be collected. Moreover, consideration was given to perform PSP in flight; however, it quickly became apparent that the timing and cost of the technological development was beyond the scope of this project. The concept was to use the laser light-sheet in combination with a surface coating to obtain the pressure data, but it only reached the idea stage in a discussion between NASA Langley researchers and key personnel from the airframe industry. In addition, since the laser system was not funded to completion, this idea had to be abandoned.

\section{Data available from CAWAP}

Seven different types of flight data were collected, as per Table 3, and four are shown schematically in figure 6. Three were pressure based - surface static pressures, boundary-layer rakes, and modified Preston tubes ${ }^{6}$; three were video-recording based - surface tufts, surface oil and surface liquid-crystals; and one was hot-film data. The pressure- and surface-flow-data are used for the purpose of establishing the effects of variation in Mach number on the local flow. These data serve as the basis for comparison with other data sets. The hot-film data are used to establish whether boundary-layer transition occurs and under what test conditions. Geometry data of the airplane upper surface was also obtained, using photogrammetry, and compared with the numerical surface description (See Ref. 2).

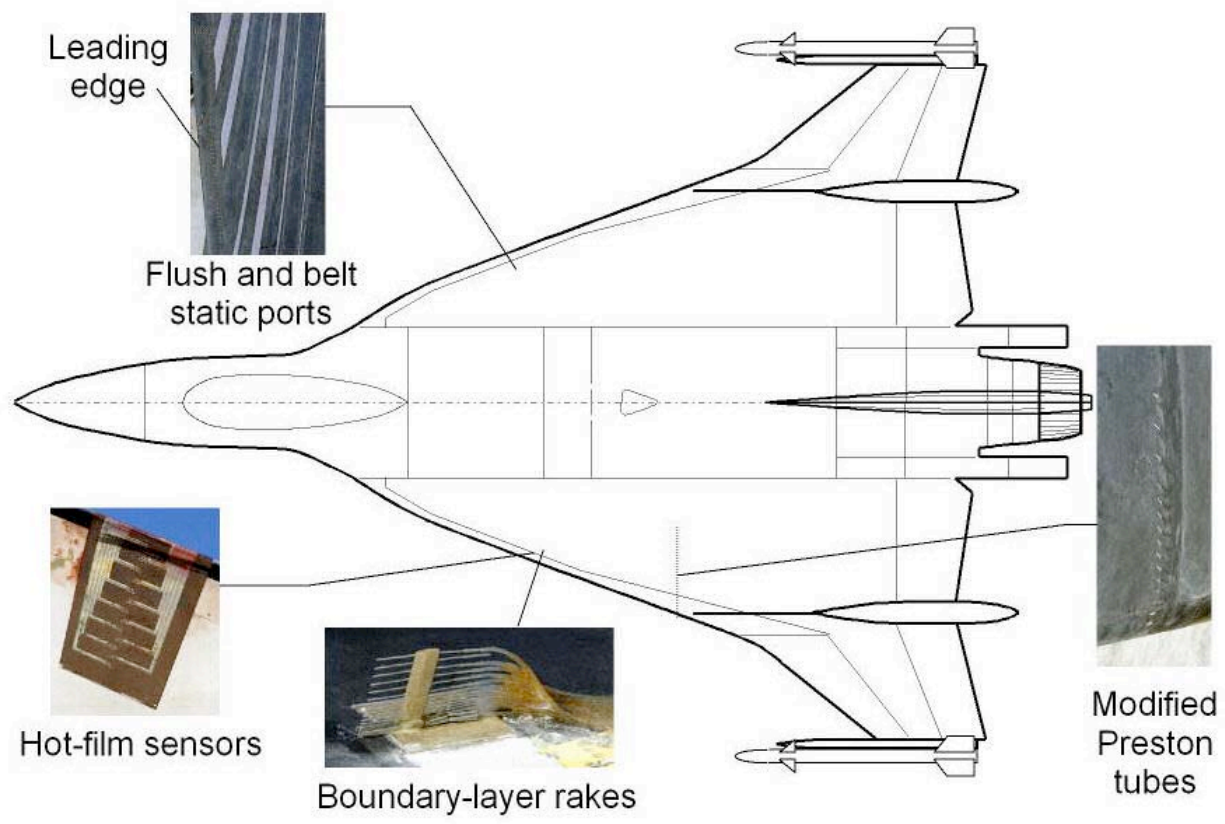

Figure 6. General layout of pressure \& hot-film instrumentation suite on the F-16XL-1 aircraft. 


\section{Pressure suite}

Figures 6 and 7 detail the complete pressure instrumentation system layout on the aircraft, including the distribution of the static ports by type, belt or flush, and boundary-layer rakes or modified Preston tubes. These static ports are connected to internally mounted Electronically Scanning Pressure (ESP) modules through tubes. Each pressure-tube in the belt was used to measure two separate values of pressure. This was accomplished by sealing each tube about halfway along its length, thereby making provision for one forward and one aft port. The actual number of static ports associated with each belt are displayed in figure 7 imbedded along the belt nominal Butt Line (BL).

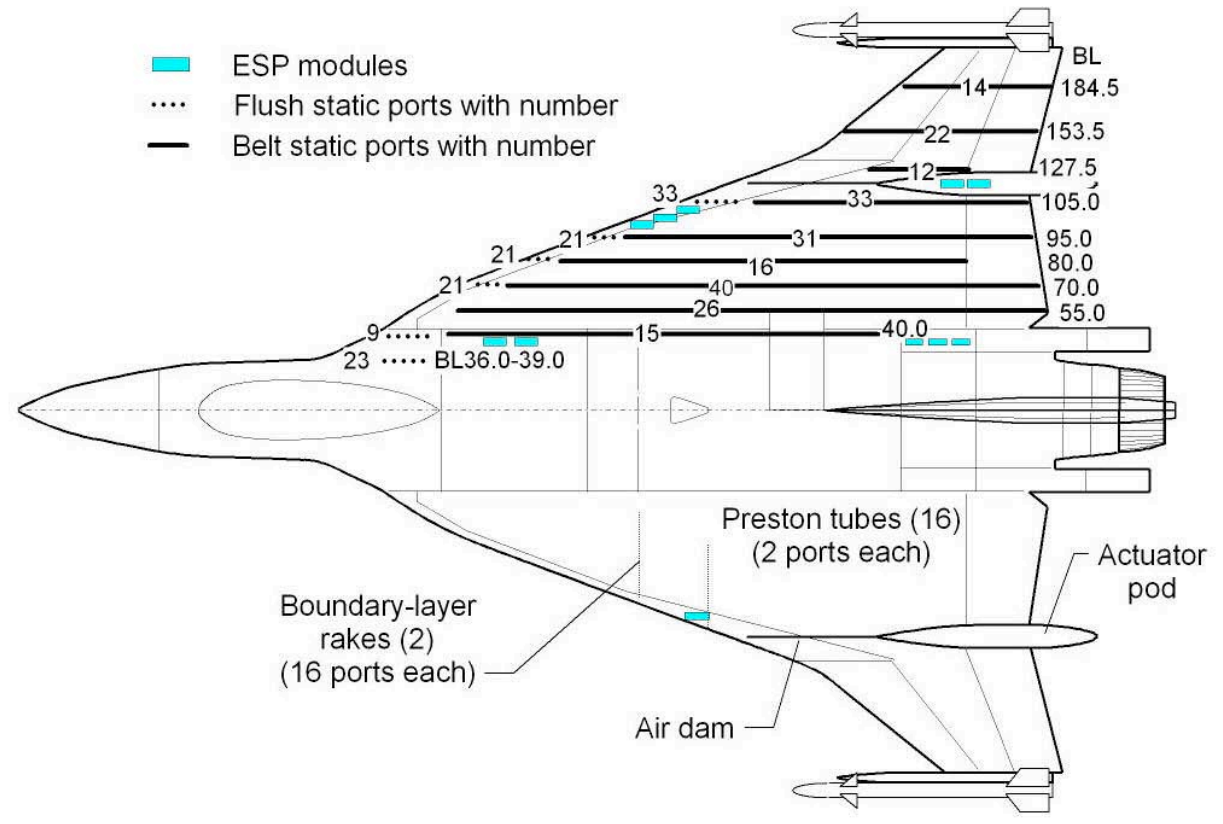

Figure 7. Details of complete-pressure-instrumentation suite and layout on the airplane.

The right-wing surface pressures - mostly upper surface - were measured using 337 static ports, both flush (LE region) and in streamwise belts, through eleven 32-port ESP transducers - also called modules. Of these 337 ports, only 326 proved to be reliable and the distribution was 280 on the upper surface and 46 on the lower. The ports were arranged so that there would be a sufficient number at a given BL or Fuselage Station (FS) for cross plotting, as well as for covering other regions of special interest; i.e., the apex and ahead of/and behind the hingelines of the trailing-edge control-surfaces.

Boundary-layer measurements were made using two, two-inch high, rakes at a time at four different positions on the left wing and the most inboard one was always used as a control. Each rake used 16 active tubes 15 total pressures and one static pressure - of the 23 available. These two rakes were connected to one 32-port ESP module located inside that wing. When mounted on the aircraft, each rake was oriented into the local flow at an average angle over its height based on initial CFD predictions from the CFL3D code ${ }^{7,8}$. The flow conditions were for the complete aircraft (half-aircraft modeled with symmetry assumed) at $\alpha=13^{\circ}, \mathrm{M}_{\infty}=0.29$ and $\mathrm{R}_{\mathrm{n}}=46.1 \times 10^{6}$; i.e. Flight Condition (FC) 7. (See Tables 4 and 5 for a listing of the FCs of interest in the current study and the associated flight and engine parameters, including those for FC7.)

Figure 8 shows the four boundary-layer locations chosen - one well inboard of the shed vortex systems (\#3), one underneath the primary vortex (\#4), and two associated with the secondary vortex. One of the latter is located underneath that vortex (\#5) and the other (\#7) at its separation point; all are at a nominal position of FS 295. The average of the local flow at- and slightly off-the-surface were used to establish the rake orientation angles for FC7. This figure also shows the relative locations of the modified Preston tubes. They were to be located at the same fuselage station as the boundary-layer rakes, but a more aft position for the tubes was necessitated due to easier aircraft installation and to avoid the flow off a step in the leading-edge region. 
The 16 modified Preston tubes (See figs. 6 and 8) - the modification to each Preston tube is the integration of a static pressure port with the total pressure tube - are used to determine local skin friction across the left wing near FS 330. These 32 pressures use the same ESP as the rakes but not on the same flight. The tubes were aligned with the local flow using the same initial CFL3D solution at FC7. The equation used to generate the EFD $\mathrm{c}_{\mathrm{f}}$ values comes from reference 5 and relates, through a process of calibration, the pressure change between the total and static tubes to the local skin friction.

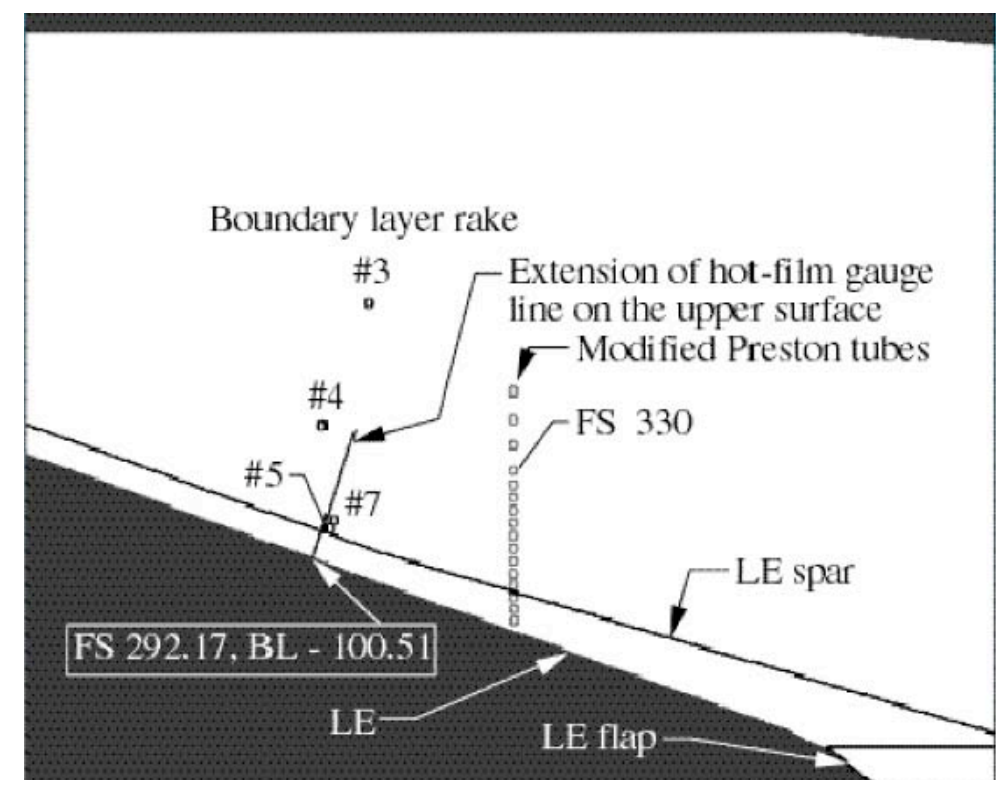

Figure 8. General arrangement of rake and modified Preston tube relative locations on F-16XL-1 left wing; Pressure instruments oriented for $M_{\infty}=0.291, \alpha=13^{\circ}$, and $R_{n}=46.1 \times 10^{6}$.

\section{B. Video suite}

Video data was recorded with up to six external cameras; two mounted atop the vertical tail, one on either side of the fuselage behind the canopy, and one in the nose of each dummy missile. An internally mounted HUD camera was also used on occasion. Figure 9 shows the camera locations on the aircraft. The time was added to each image by a time-code inserter so that the images could be compared to form a composite and so that the flight test conditions could be established. Images of interest were digitized in a 512 by 480 pixel format for further processing in order that quantifiable video data be developed. In addition to the images, the other input quantities needed for the processes are the video targets and the position and calibration characteristics of each camera/lens combination. 


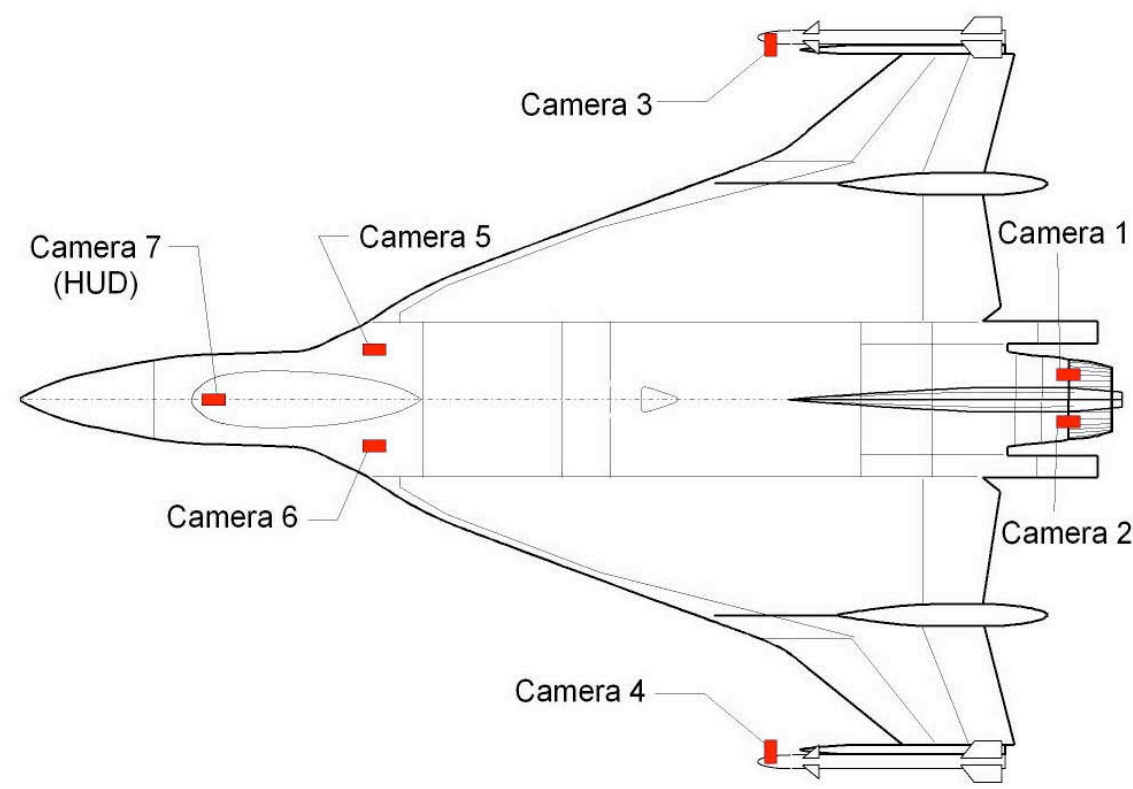

Figure 9. Locations of the video suite on the F-16XL-1 airplane.

\section{Wind Tunnel}

The second major source of data was from wind-tunnel tests with a variety of model scales. Some of these wind tunnel tests were conducted on the F-16XL configuration prior to the HSR program and others were done in direct support. These tests encompassed a variety of configurations at various Mach and Reynolds numbers. Since some of the tests were conducted with the air dams not installed, they were not applicable for comparison with flight data. The following three wind tunnel tests were primarily used for the flight and CFD comparisons.

i. A test on a 0.11-scaled model was conducted in the NASA Ames 11-Foot Tunnel prior to the start of the flight project. The test is described in reference 9 , while the actual data is tabulated in reference 10 . This model was specifically built to estimate the airloads for the airplane from $\mathrm{M}=0.60$ to 2.0 using 190 pressure ports distributed on the left-wing upper surface and the right-wing lower surface. The Reynolds numbers tested were $2.3 \times 10^{6}$ and $2.75 \times 10^{6}$, while the angle of attack varied from $-1.94^{\circ}$ to $28.75^{\circ}$. The ports were located in streamwise rows that did not nominally match the airplane. Because of data release restrictions, no direct comparisons were made with flight or CFD results. However, un-scaled transonic pressure coefficient contours were used for comparison purposes in reference 2 .

ii. The test for the 0.18-scaled model was conducted in the NASA Langley 30-by 60-Foot Tunnel at a Mach number of less than 0.08 and a Reynolds number of $2.1 \times 10^{6}$. The angle of attack varied from $-5^{\circ}$ to $30^{\circ}$ and the angle of sideslip varied from $-20^{\circ}$ to $+20^{\circ}$. In addition to force/moment and pressure data, some vapor screen images were captured. A set of pressure results was published ${ }^{2}$ and the force/moment results were published in an earlier paper ${ }^{11}$. The basic model has 30 right-wing, flush upper surface ports located to yield pressures for both streamwise and spanwise rows. The ports are nominally duplicated on the airplane for comparison. Only two runs were utilized from this test for comparison. One was a force/moment and the other a pressure, both at $0^{\circ}$ sideslip.

iii. The third wind-tunnel test used for comparison was a 0.04-scaled model in the NASA Langley Basic Aerodynamic Research Tunnel (BART). The test conditions included Mach numbers less than or equal to 0.165, Reynolds numbers less than $1.12 \times 10^{6}$, and an angle of attack variation from $5^{\circ}$ to $20^{\circ}$. This model had 82 pressure ports divided between the right upper wing surface and the left lower wing surface. The pressure ports correlated with the 0.18 -scaled model as well as being nominally duplicated on the airplane. Selected results from the BART test appear in reference 12, where they have been compared with Euler code predictions. 


\section{CFD modeling}

The last major source of data was that generated by CFD ${ }^{2}$. The flow solver CFL3D was run in the NavierStokes mode with a turbulent boundary-layer employing the Baldwin-Lomax with the Degani-Schiff turbulence model (in the $j$ - $k$ directions) on a multiblock, patched grid over a variety of wind-tunnel and flight test conditions (See Refs. 7, 8). Two separate grids were used to model half the aircraft configuration (with undeflected control surfaces) and external flow field. The initial grid had 36 blocks and was used with version 3 of the flow solver to produce the initial results upon which the locations and orientations of the surface instrumentation were set. The current grid had only 30 blocks and was used with version 5 of the flow solver to obtain the comparative solutions reported herein. The current grid was needed for two reasons; namely, to have the grid more closely conform to the actual fuselage and wing geometries, and to improve the grid layout on the wing and fuselage surfaces. The missileand missile-rail-grids were effectively the same with either grid. For the current grid, the inner region of the aircraft was modeled by 16 blocks, the outer region by 14 blocks, and all 30 blocks are shown schematically in figure 10 . The boundary conditions were symmetry, solid wall for the outer mold lines, flow into the duct-inlet but the exhaust-face was faired over, and Riemann-type conditions at the far-field boundaries. A total of 1,372,096 cells $\left(1,707,117\right.$ node points) were used to obtain solutions at specified test conditions $\left(\mathrm{M}_{\infty}, \alpha\right.$, grid $\mathrm{R}_{\mathrm{n}}$, $\mathrm{T}$, etc.). To maximize computer resource allotments, the minimum number of cells was used. The resulting grid spacing normal to the numerical surface led to a value of $y^{+}$of 2 at wind-tunnel $R_{n}$, whereas at flight $R_{n}$ the average value was $y^{+}$of 82. In an effort to compensate for the insufficient grid spacing at flight conditions, the "wall function" option was used to augment the turbulence model in CFL3D. The "wall function" is defined as that boundary-layer growth rate expected from a turbulent mean flow near the wall ${ }^{13}$.

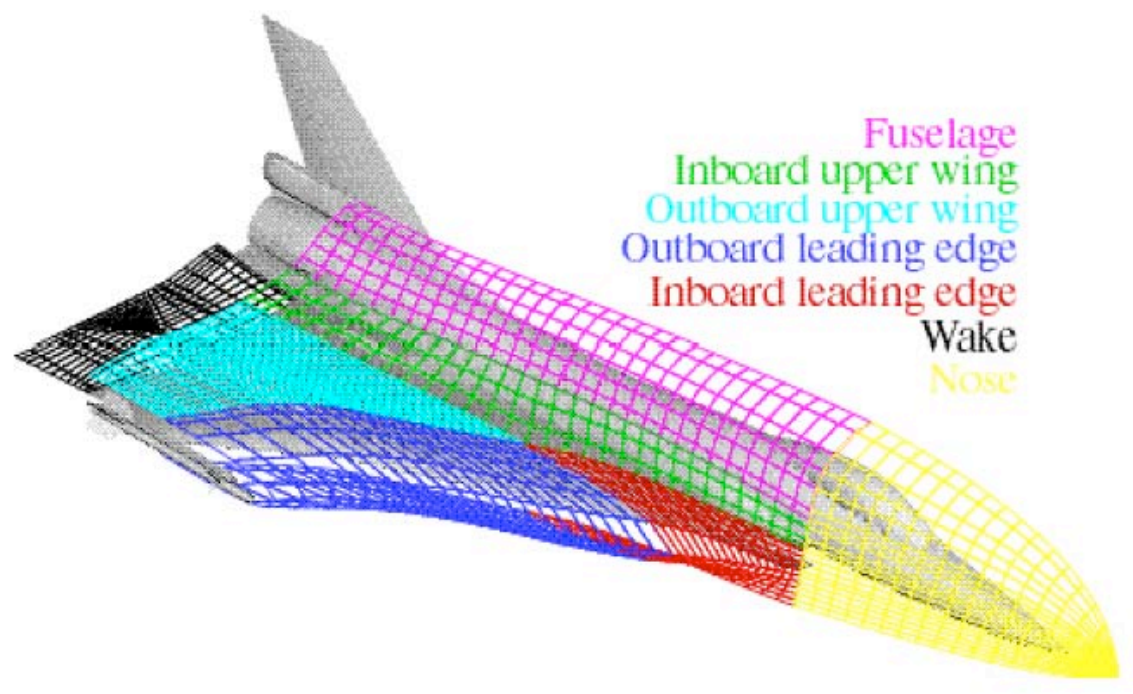

(a) Inner.

Figure 10. CFD block structure layout for F-16XL-1. 


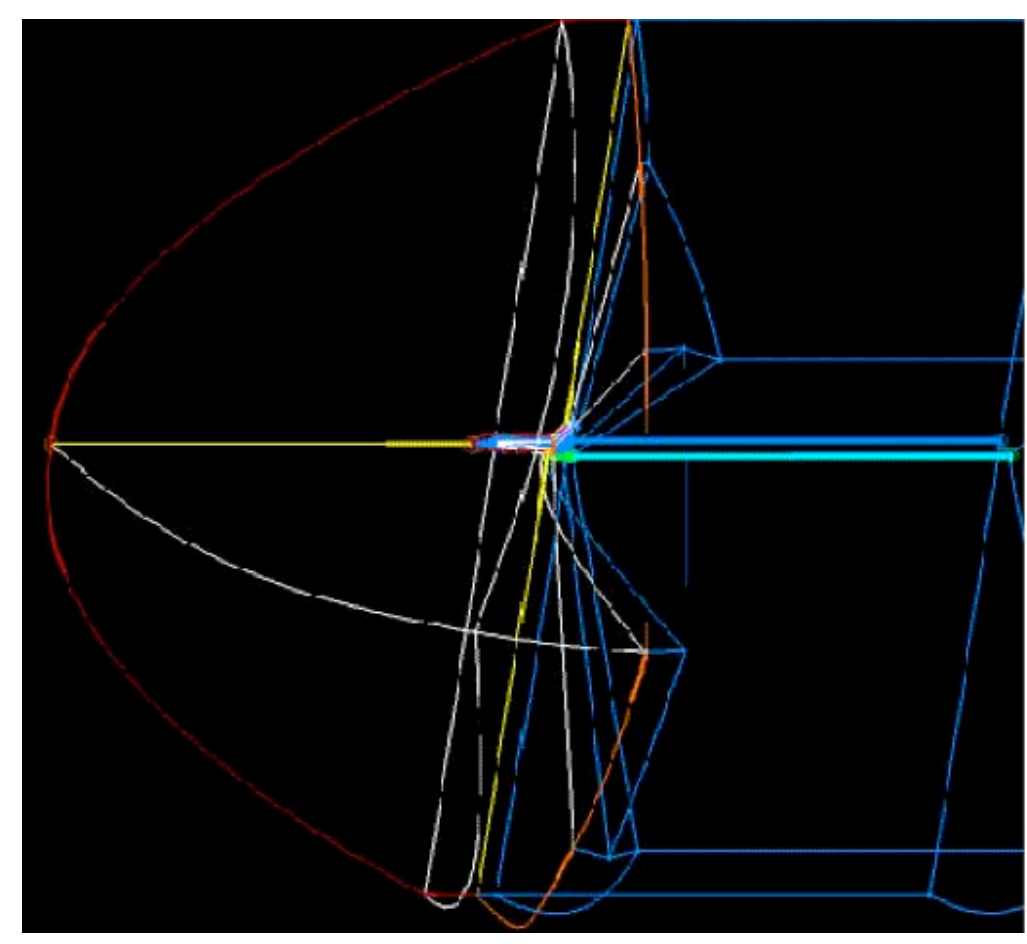

(b) Outer

Figure 10. Concluded.

\section{E. Database of results}

A database was set up, as described in Appendix B of reference 2, to facilitate data comparison between the various CAWAP sources; i.e. flight, wind-tunnel and CFD. The data types used for comparison were local surface pressures between the three sources, and boundary-layer and skin friction between the flight data and CFD predictions. Moreover, the database stores administrative information about the tests (meta-data) and the full, mass storage, path name of the resulting data files. For the Experimental Fluid Dynamics (EFD) measurements, the data stored are files of pressure, force/moment, still photographs, and two-dimensional images digitized from videotape (both instantaneous and time averaged); for CFD predictions, the grid and solution files are stored as well as $\mathrm{C}_{\mathrm{p}}$ data at selected FSs and BLs. The F-16XL-1 database also supports the viewing of 3-D renderings of the 2-D flight images through computer software tools. Queries for selected pressure data and 2-D flight image data were available to internet users by completing an appropriate on-line form on this unclassified/unlimited server. The web service was functional at the publication time of reference 2 and shortly thereafter, but has since been discontinued due to changes in policies and available resources.

\section{F. Sample CAWAP comparisons}

Selected figure samples from the CAWAP report ${ }^{2}$ are repeated as Figs. 11 to 14 . Following each set of figures is an associated commentary provided for completeness. Note that these figures may contain a legend signifying which flight and test point (run number) served as a source for the flight data; for example, Flt144.Run3b, up. These dataset associations are not the same as the FC but each one shown has a FC equivalent, as per the figure caption. 


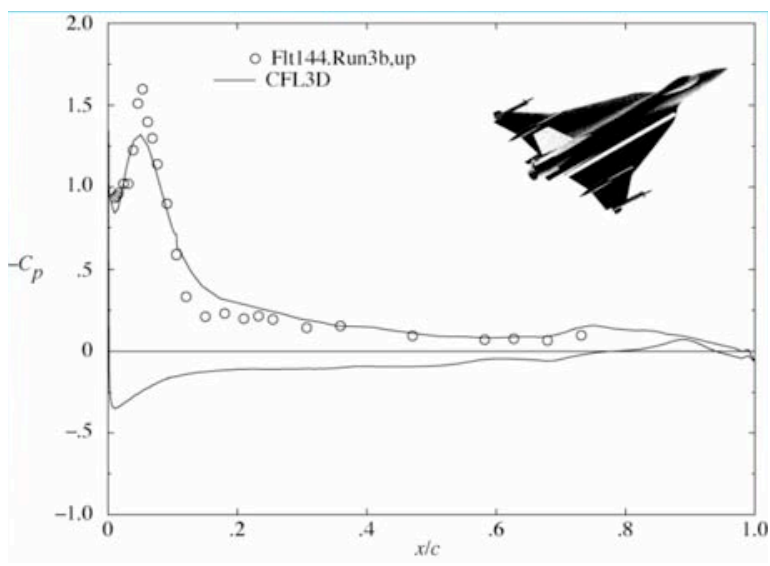

(a) BL 55 .

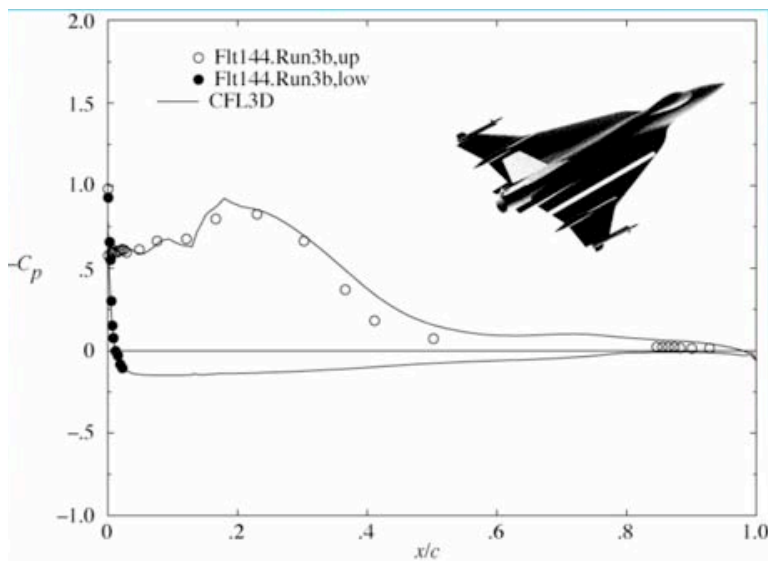

(c) BL 80 .

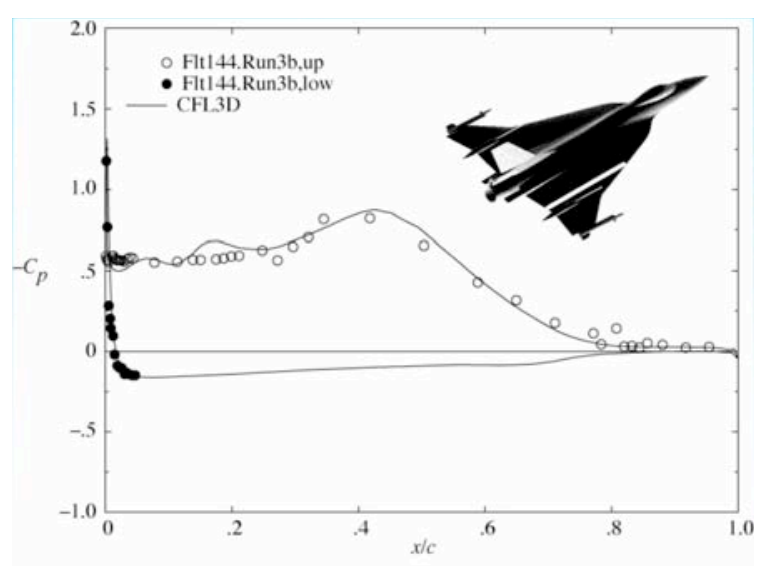

(e) BL 105 .

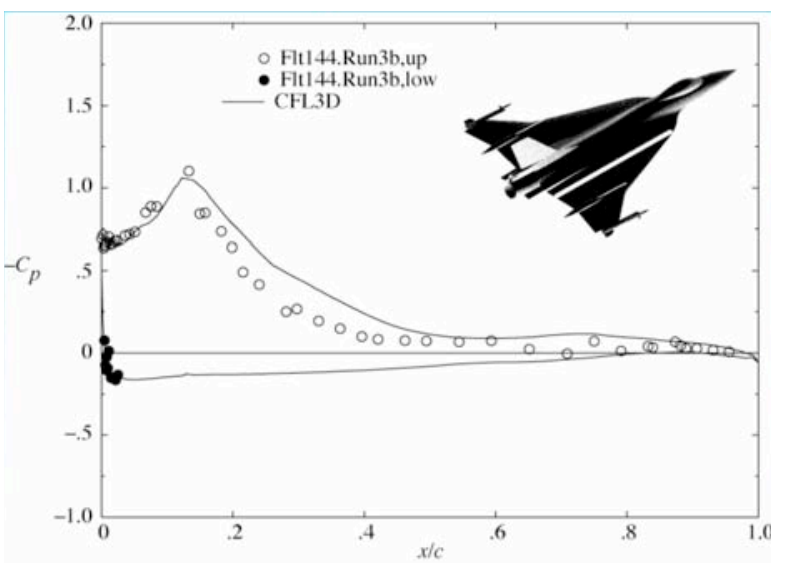

(b) BL 70 .

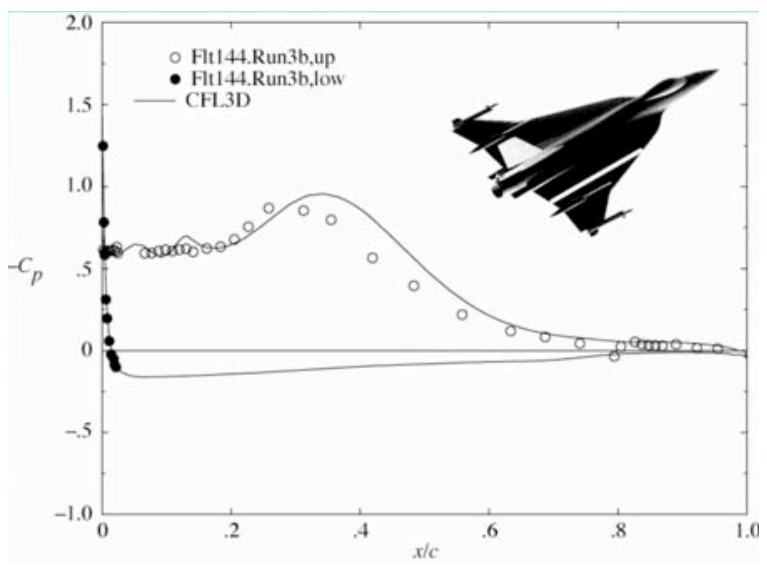

(d) BL 95.

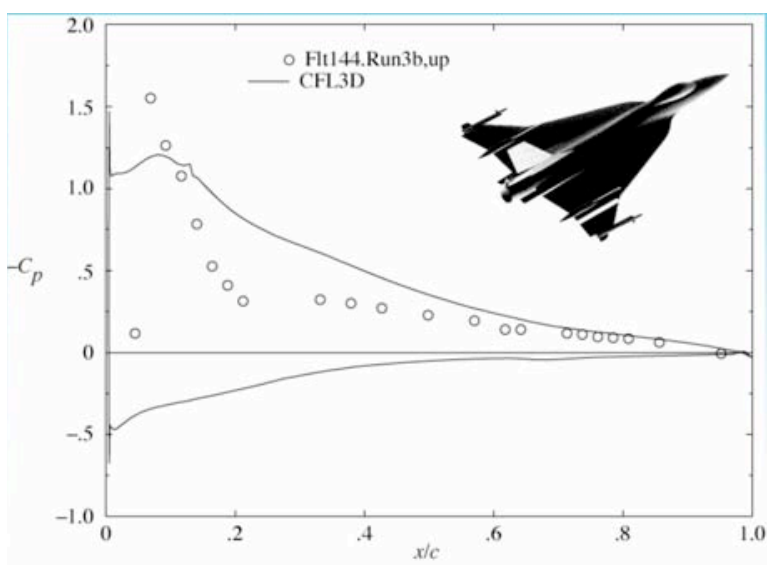

(f) BL 153.5.

Figure 11: CFD and Measured $C_{p}$ at FC46 $\left(M_{\infty}=0.527, \alpha=10.4^{\circ}, R_{n}=46.9 \times 10^{6}\right)$. 


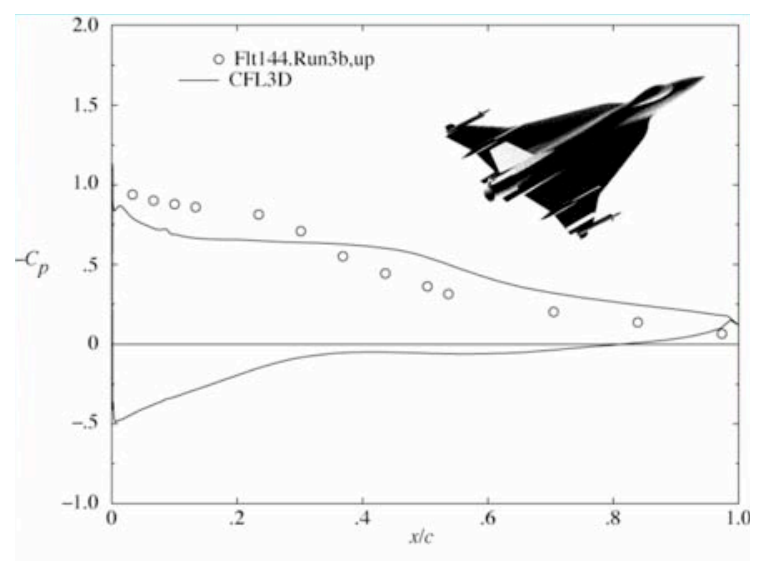

(g) BL 184.5.

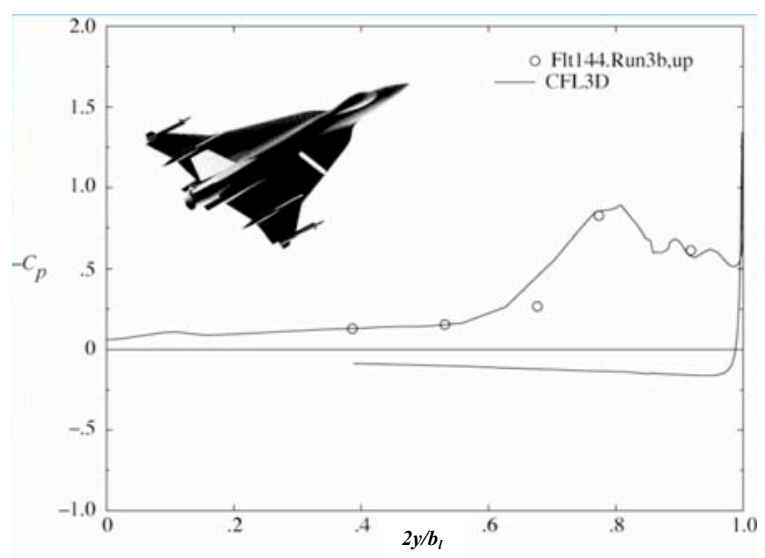

(i) FS 300 .

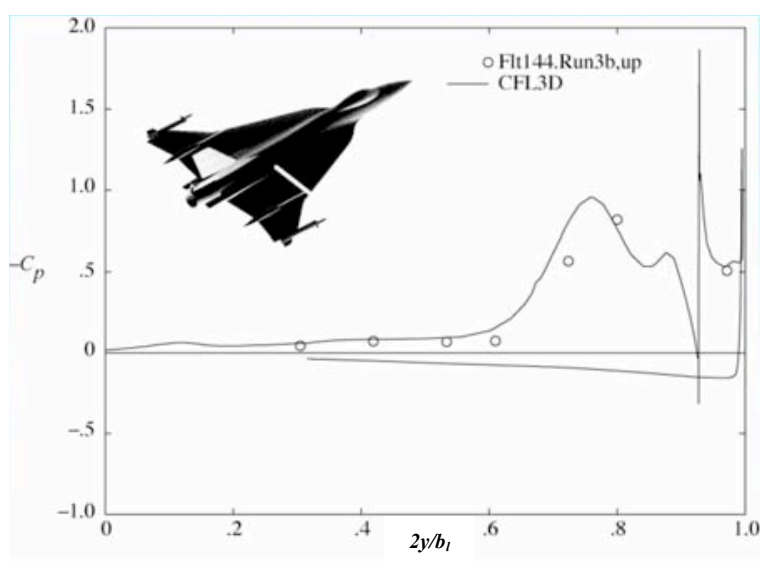

(k) FS 375.

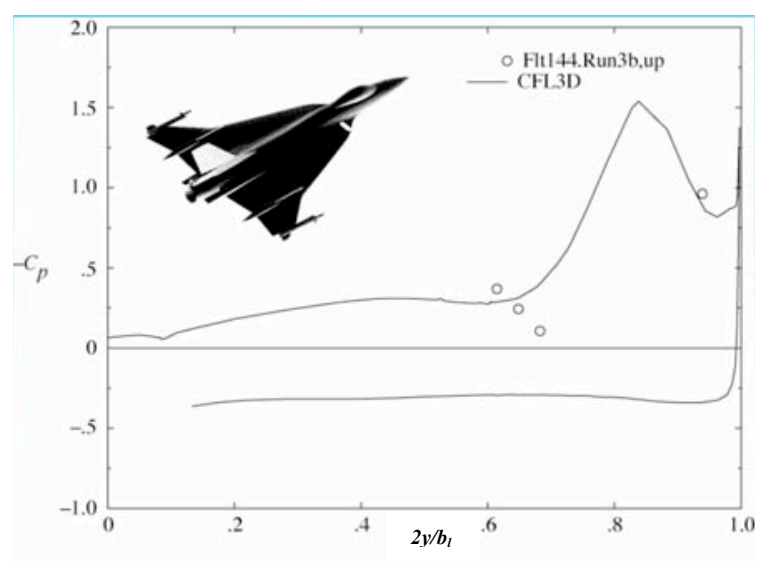

(h) FS 185.

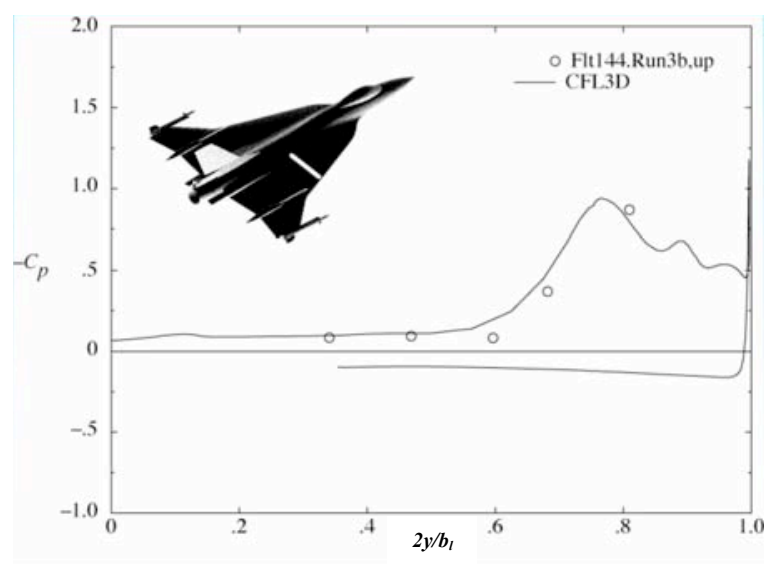

(j) FS 337.5.

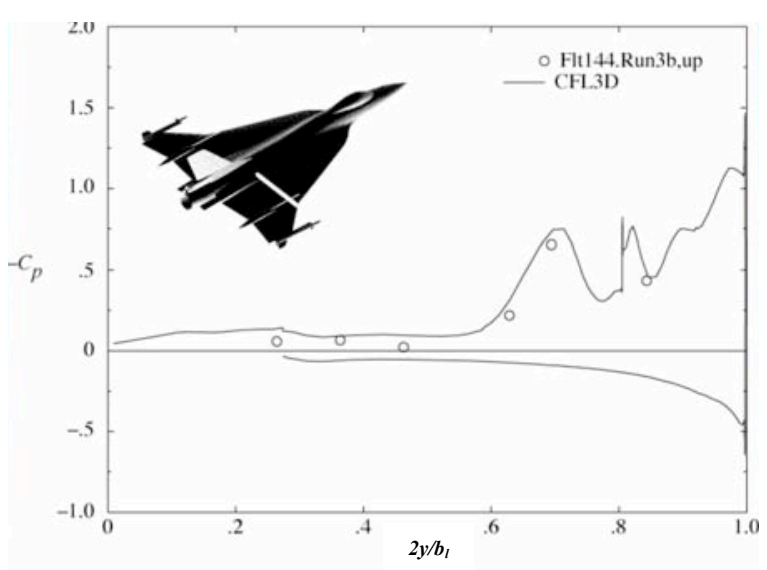

(1) FS 407.5.

Figure 11. Continued.

15

American Institute of Aeronautics and Astronautics 


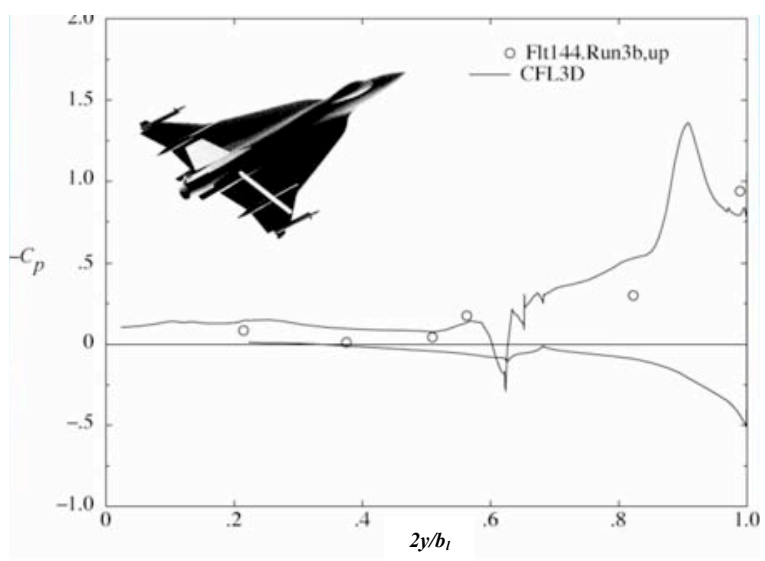

(m) FS 450.

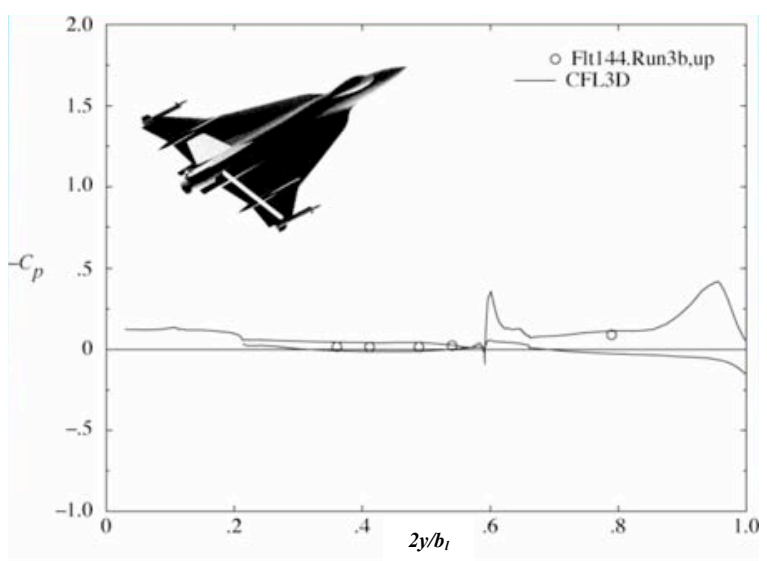

(n) FS 492.5.

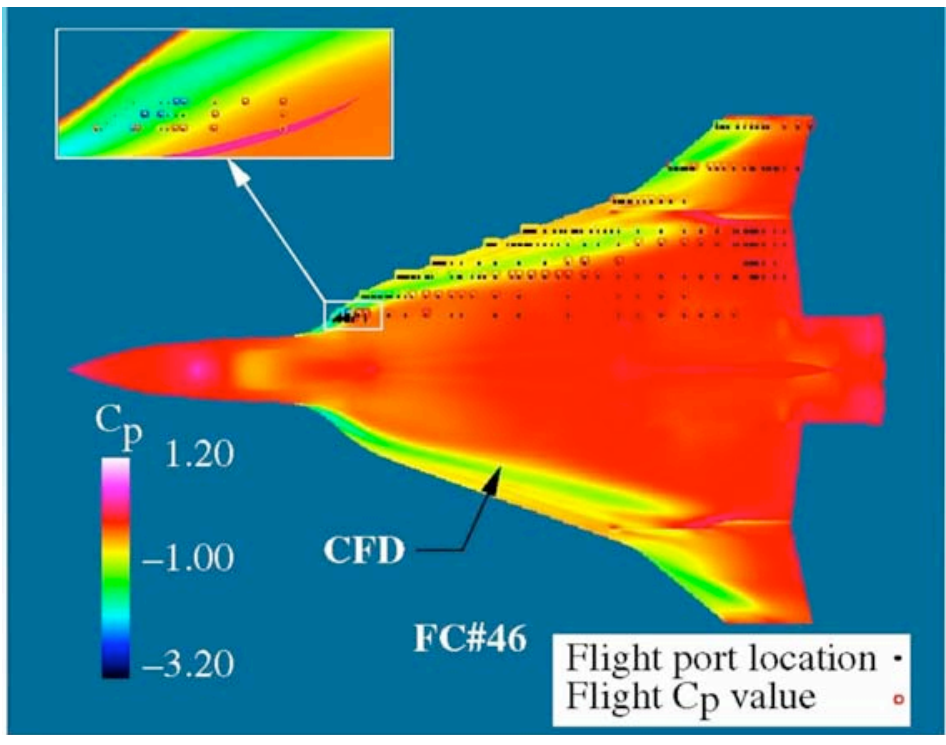

(o) Upper surface Cp distribution.

Figure 11. Concluded. 
Figures 11(a) to 11(n) show good overall agreement between the measured and predicted results at this flight condition. There are, however, three notable exceptions. The first is that the primary vortex effect on the suction peak at BL 55, the most inboard location, is under-predicted. The second is at BL 153.5 where the measured data has its primary-vortex suction-peak more forward than predicted and is followed by a more rapid compression downstream. Lastly, is the unusual and uncharacteristic variation near $2 \mathrm{y} / \mathrm{b}_{1}=0.6$ for FS 185 . The associated ports for the latter are located in and towards the aft-end portion of the S-blend curve part of the airplane, a region where the flow is very sensitive. Even with this unusual behavior of $\mathrm{C}_{\mathrm{p}}$, these results are retained because they do bracket the predicted data at this FC.

Figure 11(o) provides an overview of the upper surface $C_{p}$ comparison where the black dots represent the location of the flight ports and the associated color of the surrounding bubble indicate the measured value. Where the color of the bubble is the same as the background CFD solution, only the black dot is noted. Generally good overall agreement is seen except in the S-blend region where the measured pressures are more negative, but elsewhere the differences are such that the measured values are more positive.

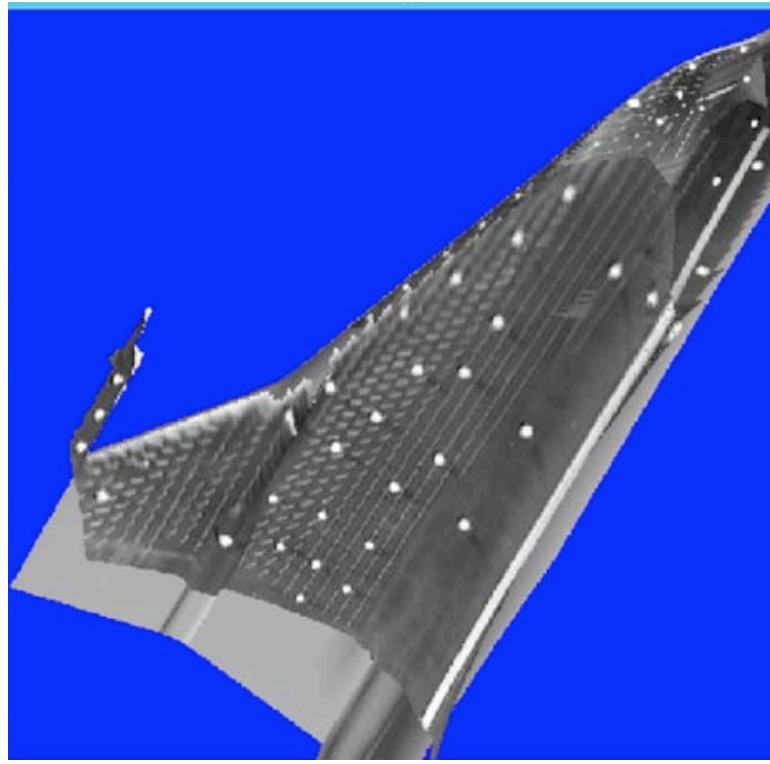

(a) Tuft images projected from three cameras onto aircraft grid.

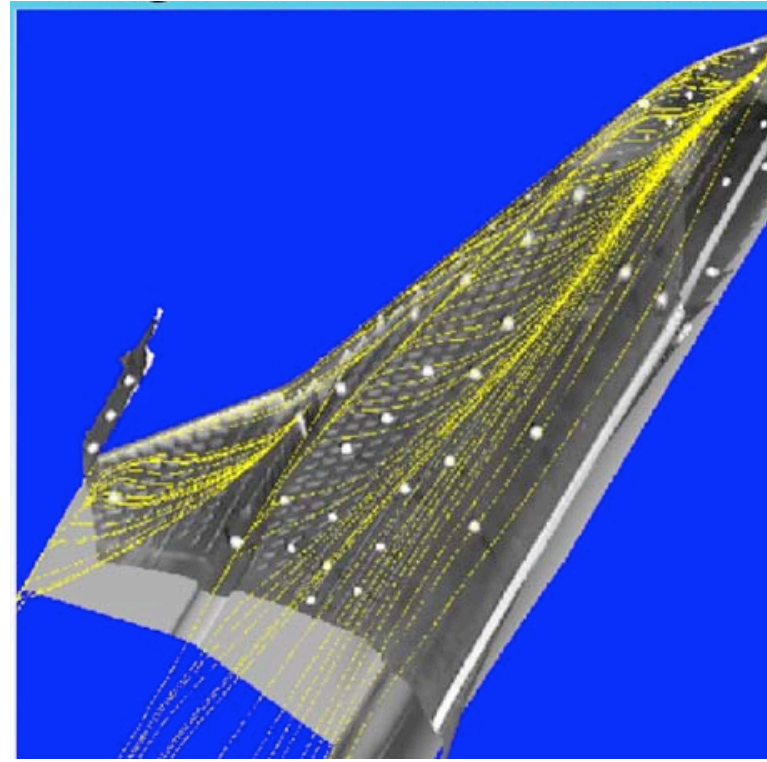

(b) Combination of tuft images and CFD surface streamlines.

Figure 12. Flight tuft data from three cameras on F-16XL-1 airplane and CFD solution at FC46 $\left(\mathrm{M}_{\infty}=0.527\right.$, $\left.\alpha=10.4^{\circ}, R_{n}=46.9 \times 10^{6}\right)$. 


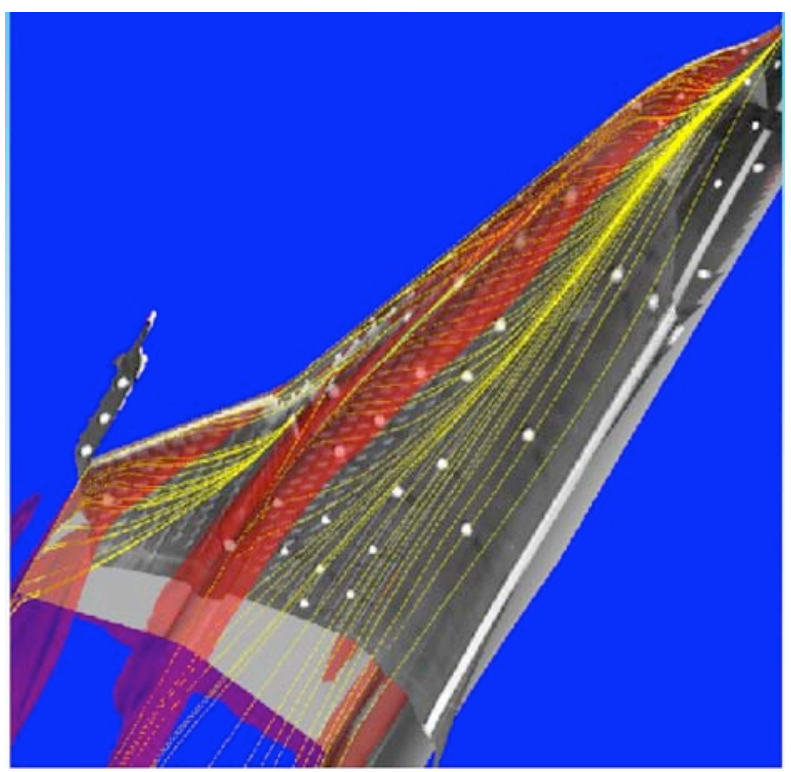

(c) Combination of tuft images, streamlines, and vortex systems.

Figure 12. Concluded.

Figure 12 shows the fusion (overlaying) of surface tuft images from the three left-side cameras (tail, missile-nose and fuselage-apex) with CFD surface streamlines and vortex-core representation for FC46. In particular, Fig. 12(a) presents the camera combination obtained by using the video targets with camera location and orientation angles. Figure 12 (b) shows that the CFD surface streamlines compare well with the flow depicted by the surface tufts. Figure 12 (c) shows the addition of the stagnation pressure iso-surfaces - at a value of 0.78 representing the locations and extent of the various airplane vortex systems - with transparency. As expected from the results of the surface comparison, the vortex system is well located with respect to the flight tufts ${ }^{1}$.

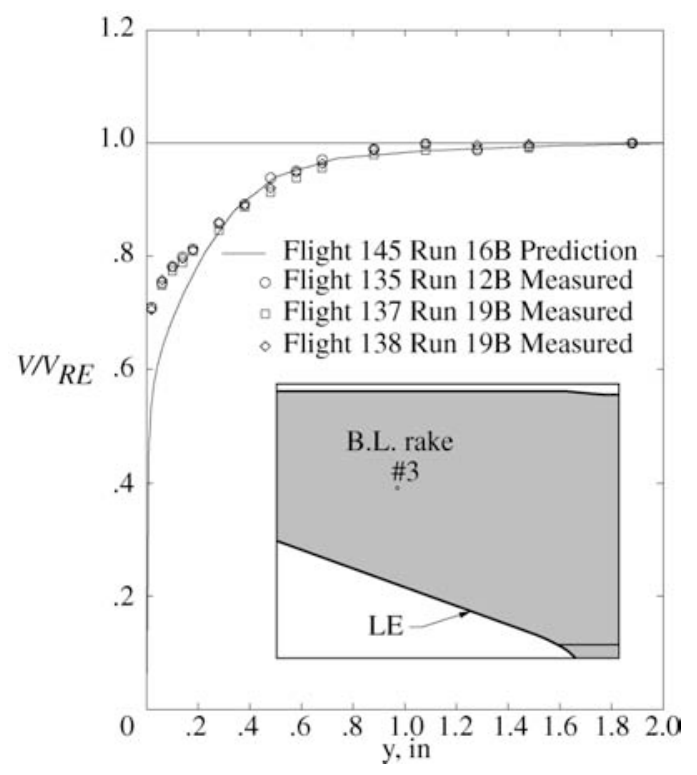

(a) Rake 3: FS 302.17, BL -52.93.

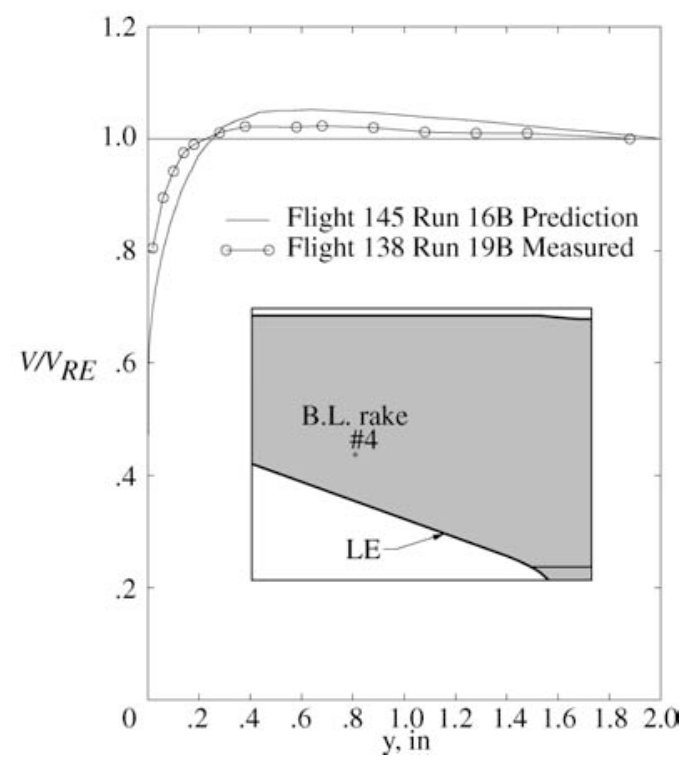

(b) Rake 4: FS 293.45, BL -76.22.

Figure 13. Predicted and measured velocity profiles for boundary-layer rakes on F-16XL-1 airplane for FC7 $\left(M_{\infty}=0.29, \alpha=11.89^{\circ}, \beta_{\text {nom }}=0^{\circ}, h=5000 \mathrm{ft}, R_{n}=44.4 \times 10^{6}\right)$. 


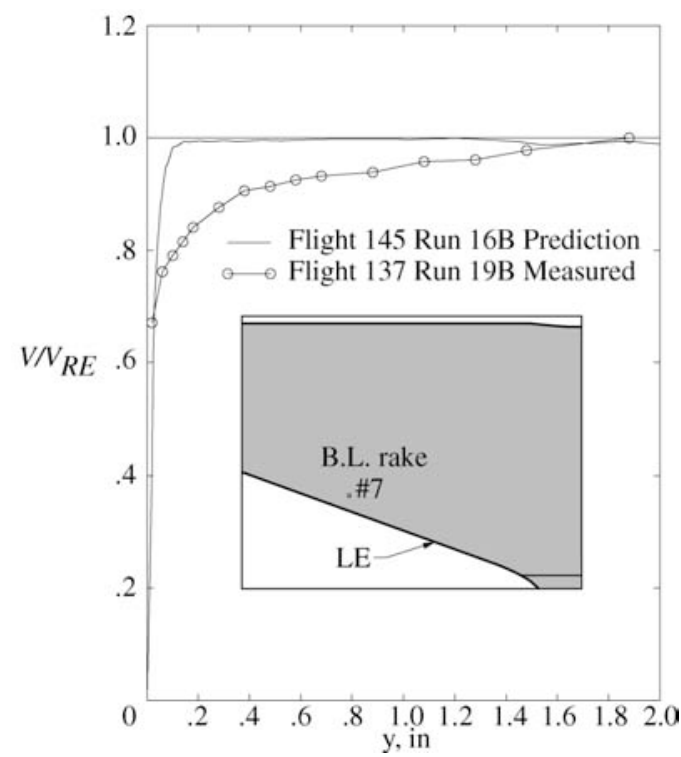

(c) Rake 7: FS 295.52, BL -94.33.

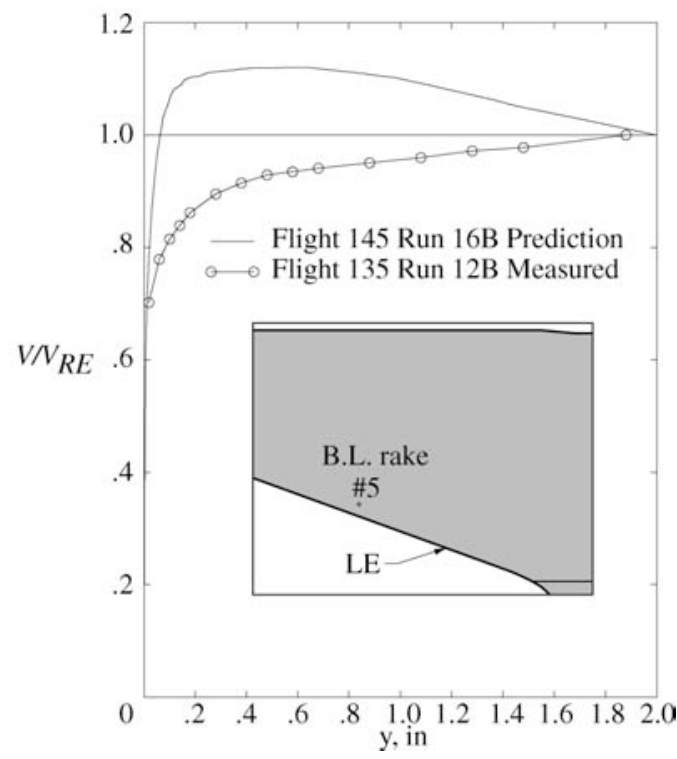

(d) Rake 5: FS 294.59, BL -96.06.

Figure 13. Concluded.

Figure 13 shows the boundary-layer profiles of measured and predicted data. The profile for B.L. rake \#3 is seen in Fig. 13(a) to be that of a classical, streamwise flow and this location was measured on all such flights to be used as a control. This figure shows good data repeatability and that the predictions agree well with them away from the wall. The data presented in Fig. 13(b) for B.L. rake \#4, underneath the primary vortex, shows that the predicted trends are seen in the measured data, including the y location for the onset of 'jet-like' flow followed by a reduction from there to the rake extreme. Figures 13(c) and 13(d) are associated with the secondary vortex, one underneath the core (\#5) and one along the secondary separation line (\#7). Two points are highlighted with respect to these two rakes data sets: the predicted values do not match the measured ones but do show how the anticipated flows would impact the boundary layer profiles; and for all practical purposes the two measured data sets are the same with a profile that does not asymptote to the boundary-layer rake extreme value. 


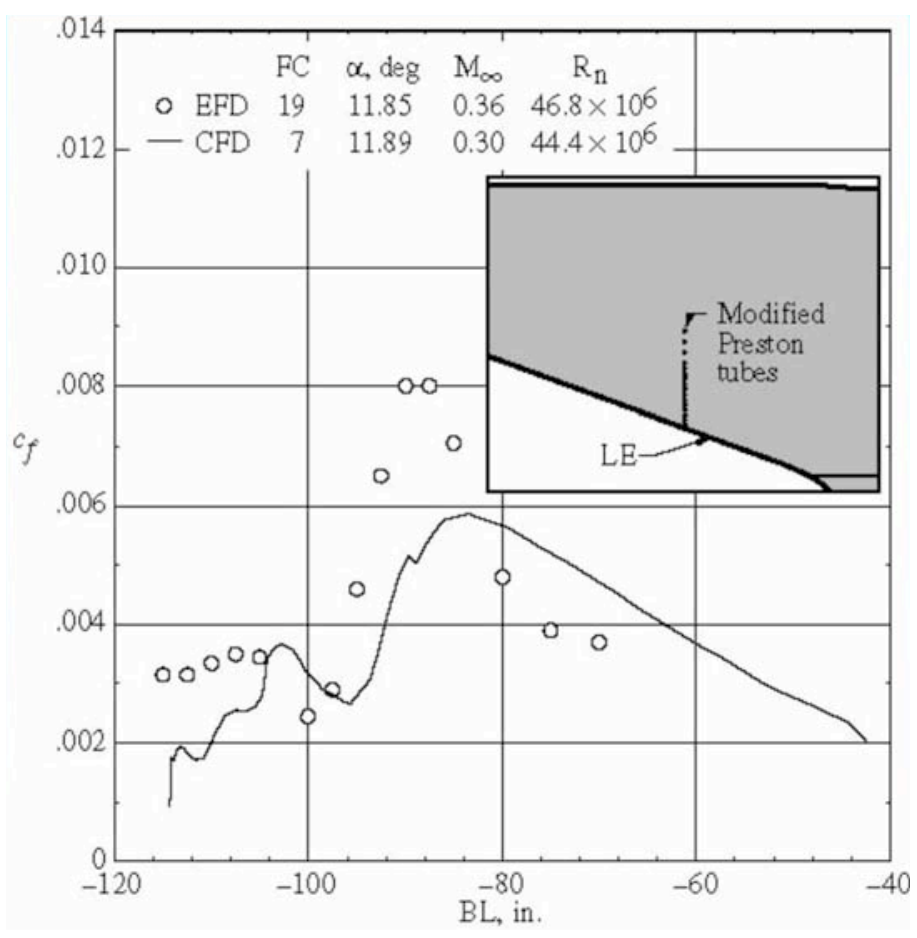

Figure 14. Predicted and measured $c_{f}$ on F-16XL-1 airplane at FS 330 for $M_{\text {avg }}=0.33, \alpha_{\text {avg }}=11.9^{\circ}$, $\beta_{\text {nom }}=0^{\circ}, R_{n, a v g}=45.6 \times 10^{6}$.

Figure 14 shows the predicted and measured local skin-friction coefficient at FS 330 for FC7 and FC19, respectively, as these FCs were quite close. High skin-friction peaks are an indication that a vortex system is present above the surface. Both sets of data show at least two such peaks. The predicted values for the primary (inboard) vortex have a different trend and reach a lower value than the measured data, and the vortex location is predicted more inboard than that measured $-\sim \mathrm{BL}-90$; however, the solution does a somewhat better job in estimating the peak value and location of the secondary vortex, albeit with two unexplained oscillations which trail toward the LE $(\mathrm{BL} \sim-116)$.

\section{CAWAPI - Organization/features/presentations}

\section{A. Organization}

At the Spring 2000 Research and Technology Organization/Applied Vehicle Technology (RTO/AVT) Symposium week held in Braunschweig, Germany, this international group was asked whether there was interest in predicting the flight results around the F-16XL aircraft - as the report ${ }^{2}$ documenting the work was in the process of being readied for publication. As a consequence, the Performance, Stability \& Control and Fluid Physics (PSF) Technical Committee established an Exploratory Team (ET) to assess interest among the member nations on this and related topics. During the ensuing year, a team was constituted and, at their first meeting in Loen, Norway, in the spring of 2001, they examined a variety of vortical flow topics that could lead to task groups or symposia. A total of five topics were offered for consideration. Some went forward individually, while others were combined in order to gain AVT Panel recommendation for acceptance and Research and Technology Board (RTB) approval.

In particular, two topics presented at the Loen Symposium on "Vortex Flows and High Angle of Attack", during the 2001 spring RTO meeting week, were put forward separately for further study. They were the CAWAP ${ }^{14}$ and the Vortex Flow Experiment - Number 2 (VFE-2) ${ }^{15}$ - both of which dealt with vortical flows around slender aircraft or wings. In the fall of 2002, these two topics were merged into a single proposal that the AVT Panel could recommend for approval by the RTB. Success was achieved in the spring of 2003 when the RTB granted approval for AVT-113 and authorized its first meeting to commence during the upcoming RTO/AVT Symposium week. The title of the task group is "Understanding and Modeling Vortical Flows to Improve the Technology Readiness Level for Military Aircraft". Even though integrated, each topic had its own facet lead, and these leaders became the cochairmen of the task group. The title for the expansion of CAWAP activity to the International aerodynamics 
community within the RTO was denoted as CAWAPI. This name was crafted in advance in anticipation of approval and involved using a Virtual Laboratory (VL) at NASA Langley for facilitating secure data storage and transmission (See Refs. 16, 17)

\section{B. Features}

The features of the CAWAPI are contained in the foundational document for the task group known as the "Terms of Reference" - an internal RTO/AVT panel document. In particular, there are basically three objectives to be performed under this task among the participants. They are detailed as follows:

i. Assessing various CFD codes against F-16XL-1 flight, and perhaps wind-tunnel, data sets in order to increase the Technology Readiness Level of the respective codes to a value of 5 ("Component and/or breadboard verification in a relevant environment").

ii. Developing best practices for each code based on the data sets.

iii. Incorporating appropriate or upgraded turbulence models into the respective codes to provide for improved agreement.

These were to be accomplished by having each of the participating groups be responsible for certain aspects of the work. For example, each participating group will use their best efforts, consistent with program priorities and funding, to perform the agreed upon detailed tasks, and to be responsible for providing its own resources for the completion of this task. In particular, NASA agreed to do the following:

i. Supply export-controlled geometry in various formats (iges, structured grid and unstructured grid) of the F-16XL-1 aircraft to participating partners once formal Memorandum-of-Agreements are in place.

ii. Make available flight pressures, images, skin-friction and boundary layer measurements to the team.

iii. Supply data format to and coordinate database services needed by the group.

iv. Coordinate the various efforts and arrange for meetings each 6 months in conjunction with RTO Symposium.

v. The completion date of this task should be a maximum of 3 years after all approvals are granted. The initial ending date was set for December 2005, but this was later extended to December 2007, due to a variety of factors.

The fact that the aircraft geometry was restricted by 'International Traffic in Arms Regulations' (ITAR) complicated the process of NASA fulfilling its obligations until it was realized that a Virtual Laboratory, housed in an electronically secure DeMilitarized Zone, was a solution for geometry and grid transfers among participants. Details about this have been documented ${ }^{16,17}$. Accessibility to both old and new data was provided through the VL to the participants. After the conclusion of the task group, it was anticipated that portions of the database would be made widely available via the VL, but that is highly unlikely given the current environment.

The CAWAPI facet work was facilitated by having well-known and highly respected organizations/researchers as members of this international effort working under the RTO "umbrella". These organizations appear in the following list grouped according to their basic function. They include four airframe companies - EADS-Munich (Germany), Turkish Aircraft Industries (Turkey), Boeing-St.Louis Phantom Works (USA), and Lockheed Martin Aeronautics Company - Fort Worth (USA); two government research laboratories — NLR (The Netherlands) and NASA Langley (USA); and six university led efforts - KTH/FOI (Sweden), University of Glasgow/Liverpool University (United Kingdom), Vrije Universiteit Brussel (VUB)/NUMECA (Belgium), University of Tennessee-Chattanooga/SimCenter (USA), United States Air Force Academy (USA) and University of Wyoming (USA). Unfortunately, not all of these were able to continue to the end of this facet, and some optioned to continue in the VFE-2 facet instead.

\section{Presentations}

The original CAWAP solutions were obtained using a structured grid solver, based on a documented iges file with refinements, compared with measured flight data, and reported in reference 2 for the F-16XL-1 aircraft. It was anticipated that the new solutions would require both structured and unstructured grids. Rather than just use the same iges file as before, it was decided to reinvestigate the geometry, find the best iges file available, and make certain that it was equally suitable for both solver types. The new iges file is only slightly different from the 
previous one, but it satisfied both 'grid' communities. The process of obtaining grids for both structured, as well as unstructured, solvers from this iges file is detailed in reference 18 and Fig. 15 is a sample from that paper.

When the CAWAPI computational effort commenced, the majority of those performing computations planned to do so using structured grid solvers; however, in the ensuing years that trend has reversed and now the majority are using unstructured grid solvers. A partial reason for this movement has been the improvements made in these solvers that include the potential and actualization of breaking a solution down into components for parallel processing, and the potential for automatic grid generation. Both of these can lead to significant time reductions from geometry specification to solver results. In the listing of papers that follow, authors have utilized their solvers - structured $^{19-21}$ or unstructured ${ }^{22-28}$ - in order to determine the best practices for each code and type of flow combination and then made comparisons with either other predictions or flight data as they deemed appropriate. Each of these papers has its own focus, but also contains common comparisons. For example, reference 19 emphasizes surface streamlines and understanding the relation with the off-surface flow, as shown by the sample Fig. 16. A variety of aircraft modeling studies were performed in reference 20 with the results for the complete aircraft shown in Fig. 17. References 21, 24 and 28 emphasize the effects of various turbulence models and are shown by sample Figs. 18, 19, 20, respectively. Reference 22 emphasizes solution adaptive grids, as shown by the sample Fig. 21, and reference 23 emphasizes time-accurate solutions, which is illustrated by Fig. 22. Figure $23^{27}$ shows streamlines and the $\mathrm{x}$-vorticity component for FC50 where $\beta=+5.31^{\circ}$. Lastly, reference 29 provides a summary of the "Lessons Learned" as a result of this computational effort, including its impact on the Technology Readiness Level of the examined current solvers.

An initial group of four flight conditions with either vortex-dominated or transonic flows were adopted by this facet for prediction and comparison. These were later expanded to seven and included two sideslip conditions (See Table 4). Associated with each was a set of pressure/temperature/Mach number values for a generic engine (See Table 5).

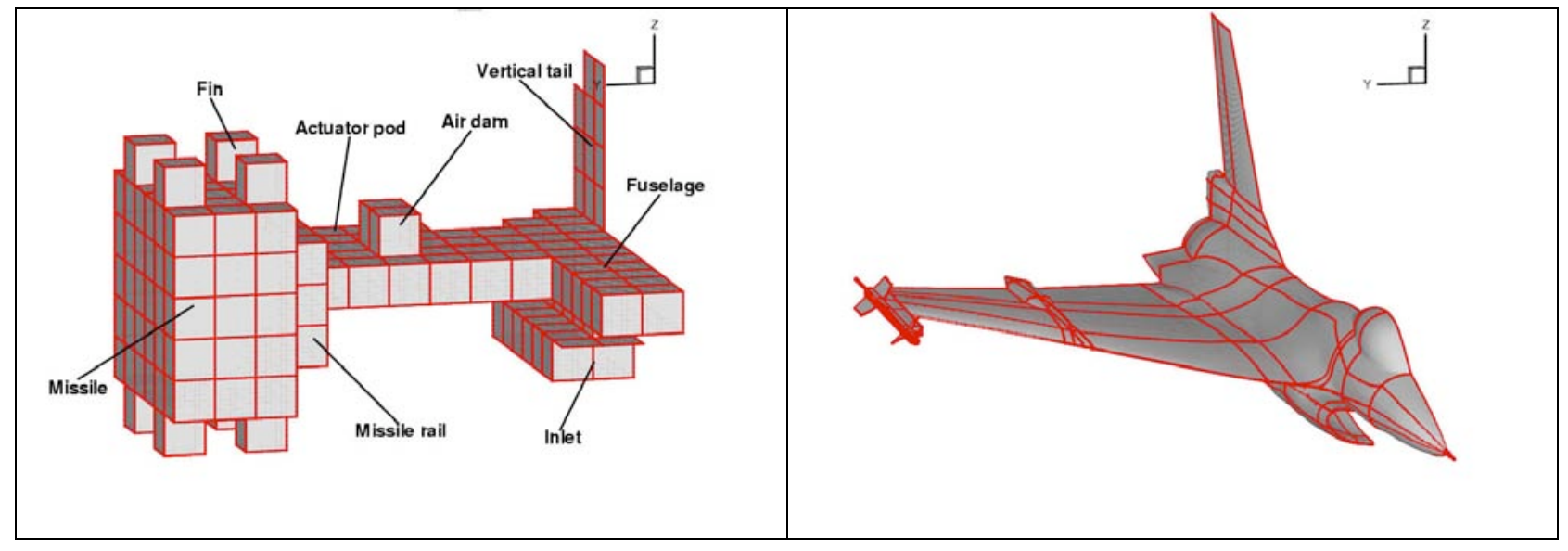

Figure 15. Abstraction of the surface geometry (left) and projected abstraction (right) for the F-16XL half-span model from Boelens,et.al. ${ }^{18}$. 


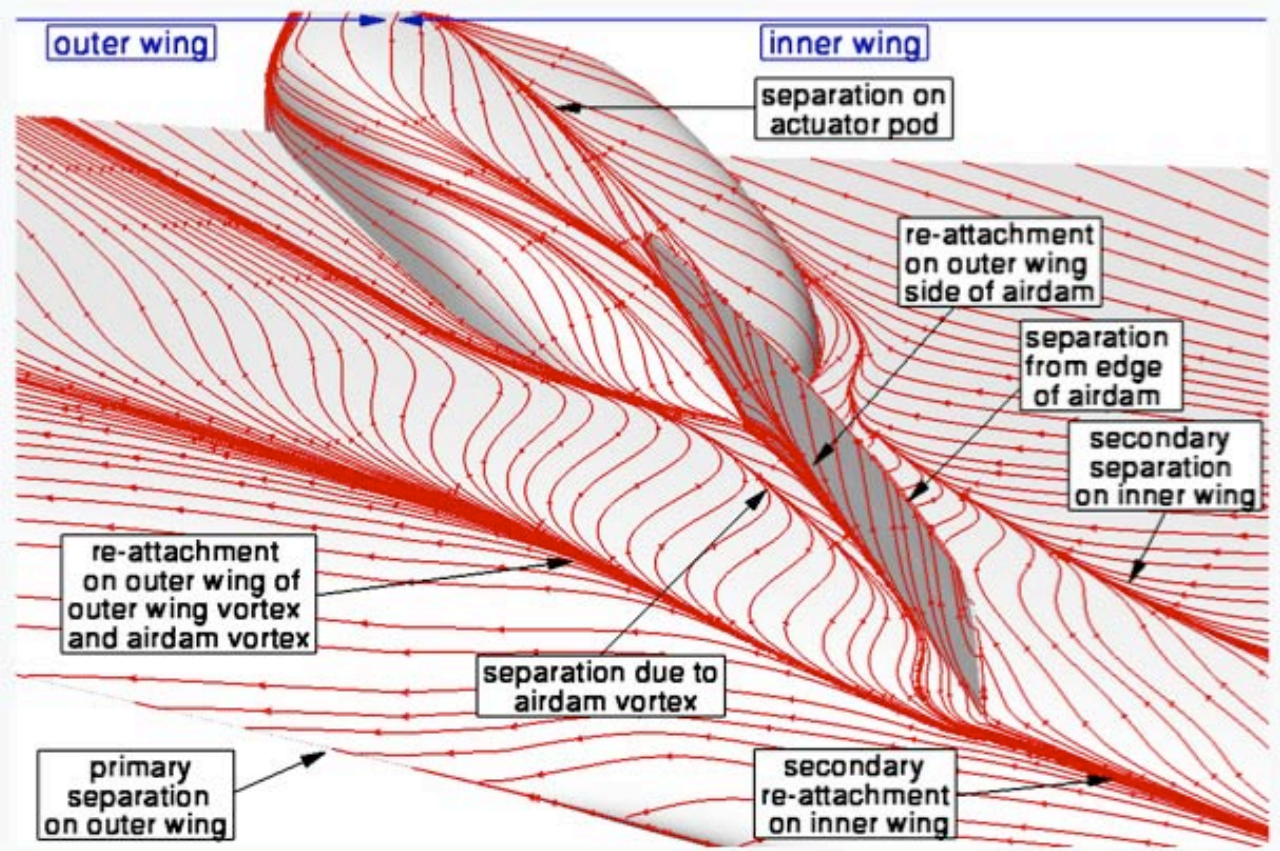

Figure 16. Surface streamlines with interpretation for $\mathrm{FC} 7$ from Boelens, et.al. ${ }^{19}$.
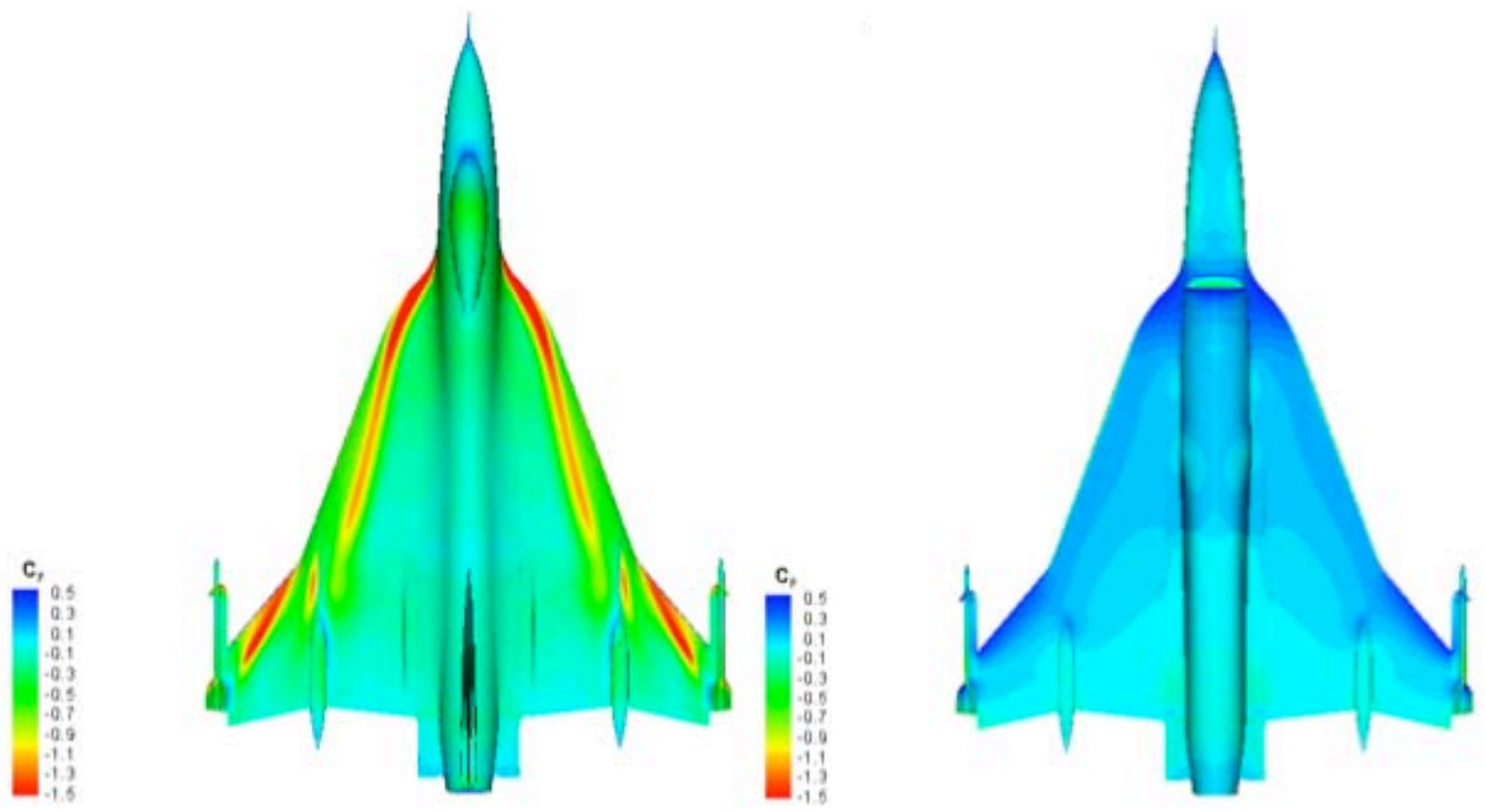

Figure 17. Upper and lower surface $C_{p}$ results for FC7 from Badcock ${ }^{20}$. 


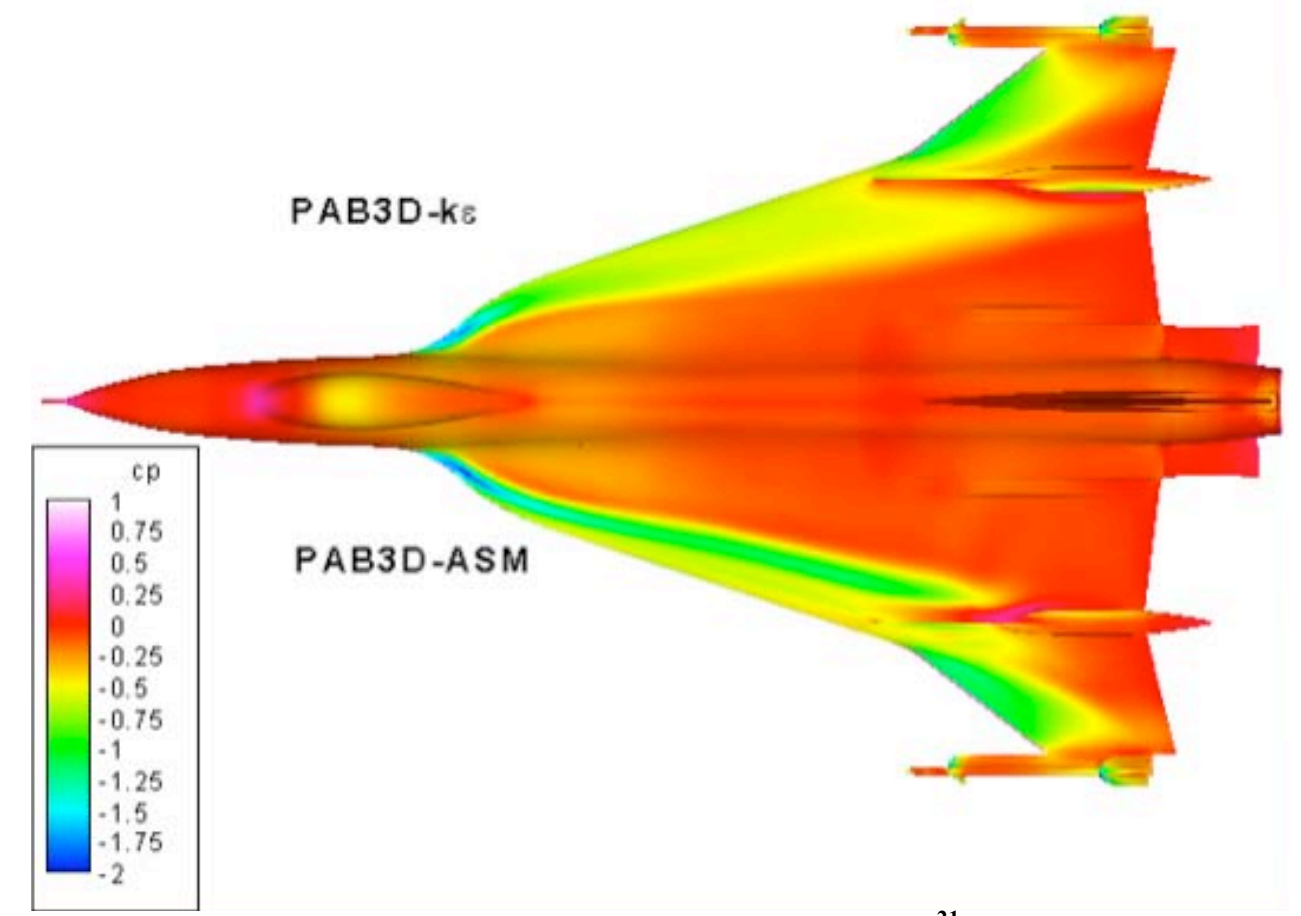

Figure 18. Turbulence modeling effect on $\mathrm{C}_{\mathrm{p}}$ for FC46 from Elmiligue, et.al. ${ }^{21}$.

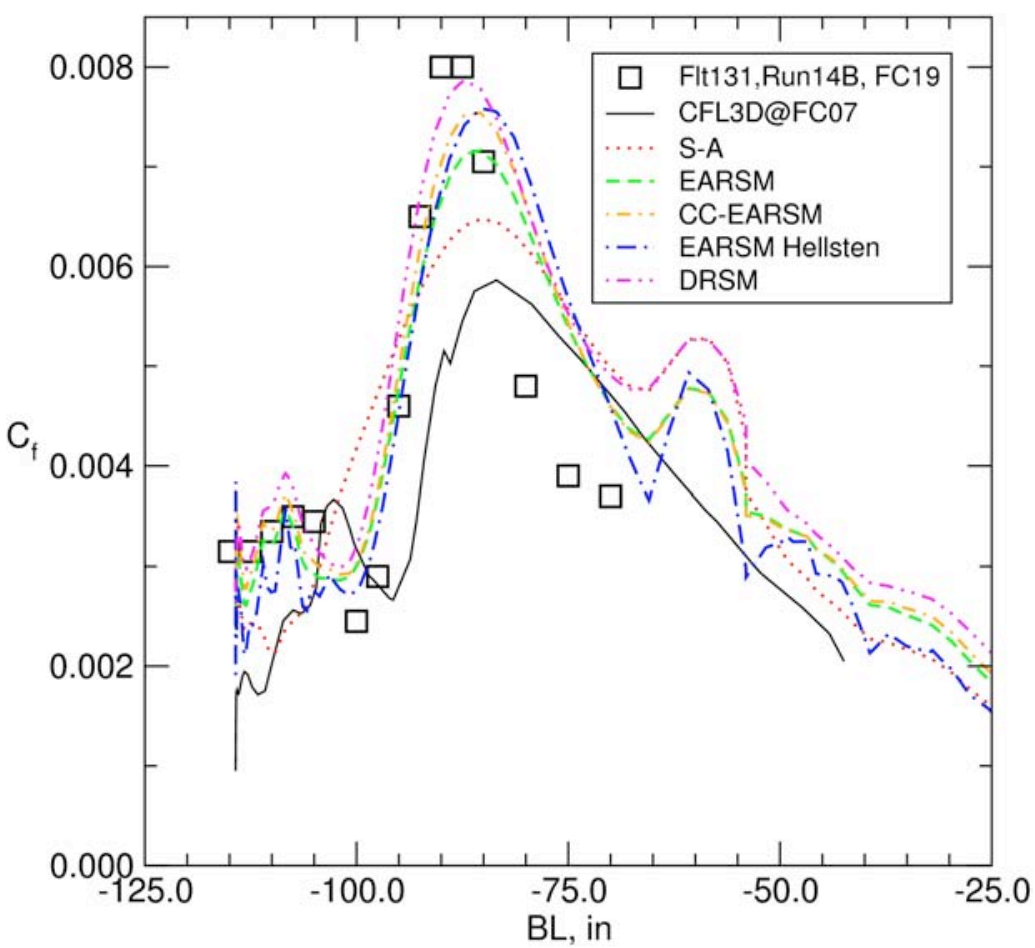

Figure 19. Turbulence modeling effect on $\mathrm{C}_{\mathrm{p}}$ for FC25 from Goertz, et.al. ${ }^{24}$. 


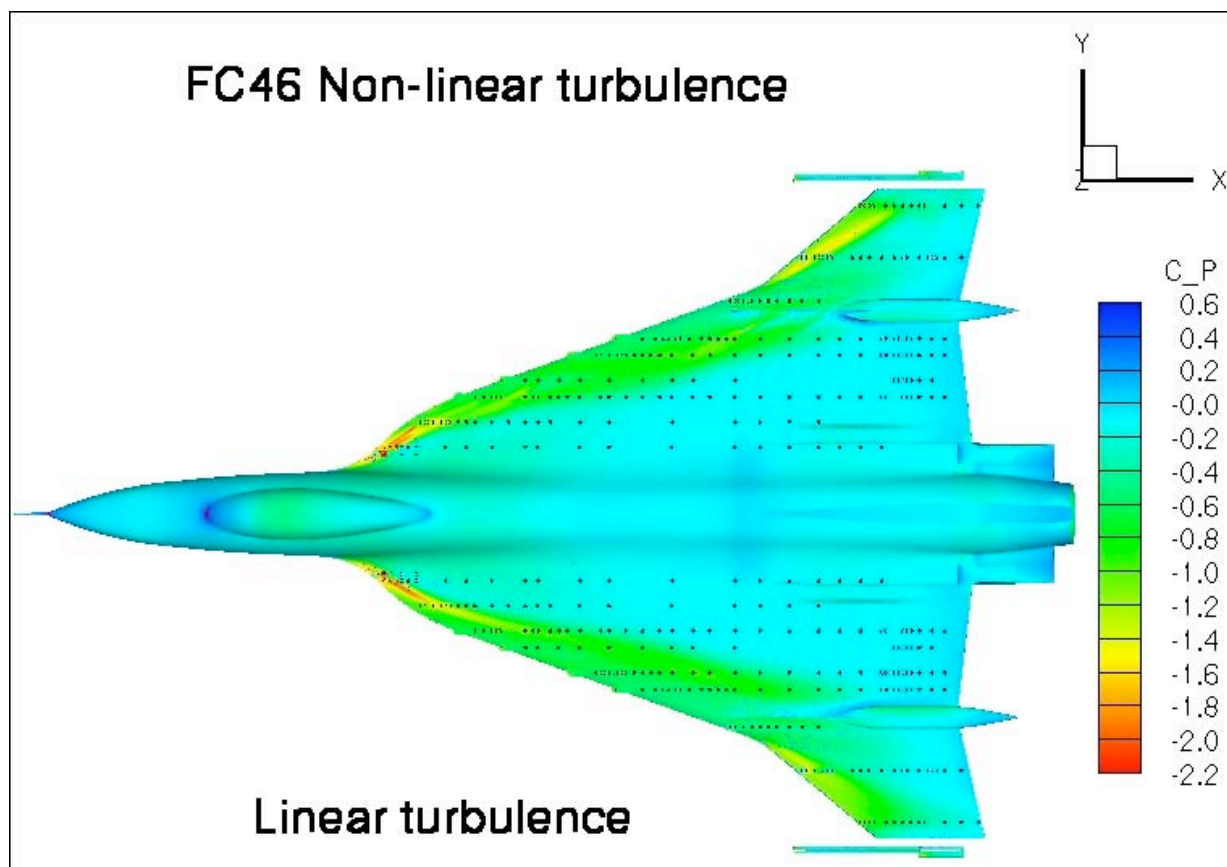

Figure 20. Turbulence modeling effect on $\mathrm{C}_{\mathrm{p}}$ for FC46 from Lamar, et.al. ${ }^{28}$.

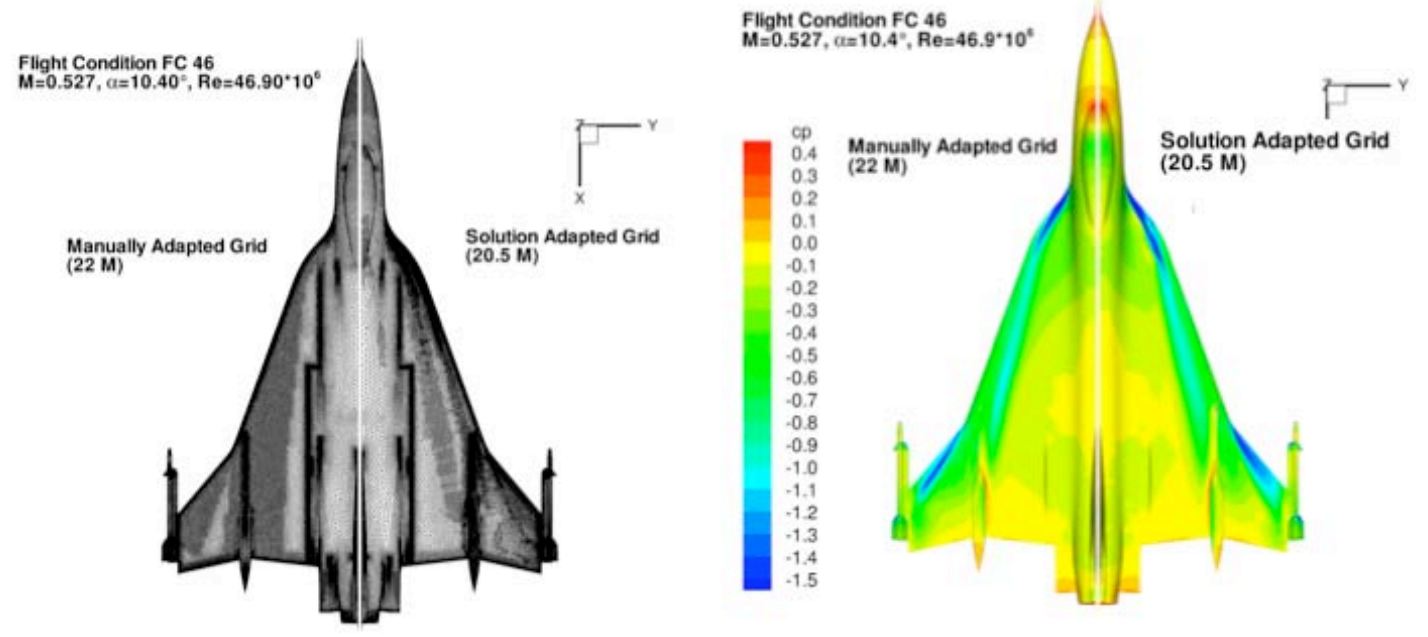

Figure 21. Solution adaptive grid effect for FC46 from Fritz ${ }^{22}$. 


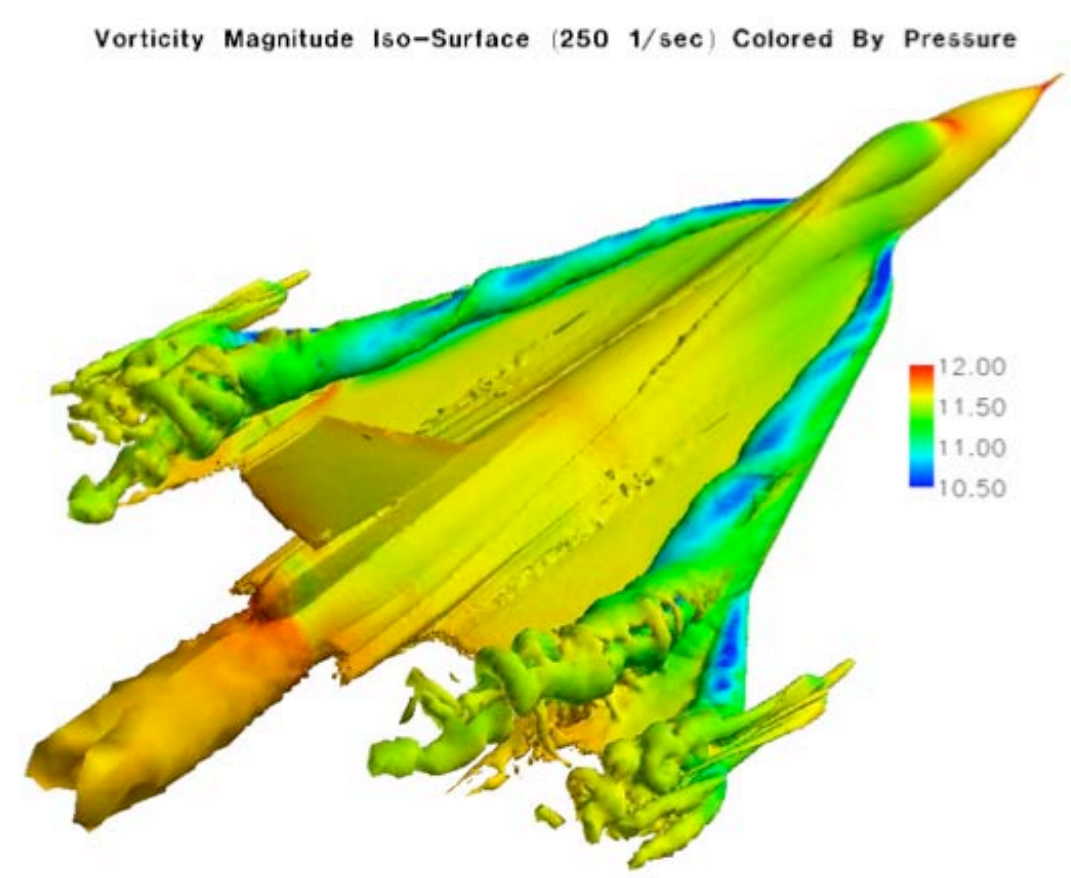

Figure 22. Time accurate solution for FC19 from Morton, et.al. ${ }^{23}$.

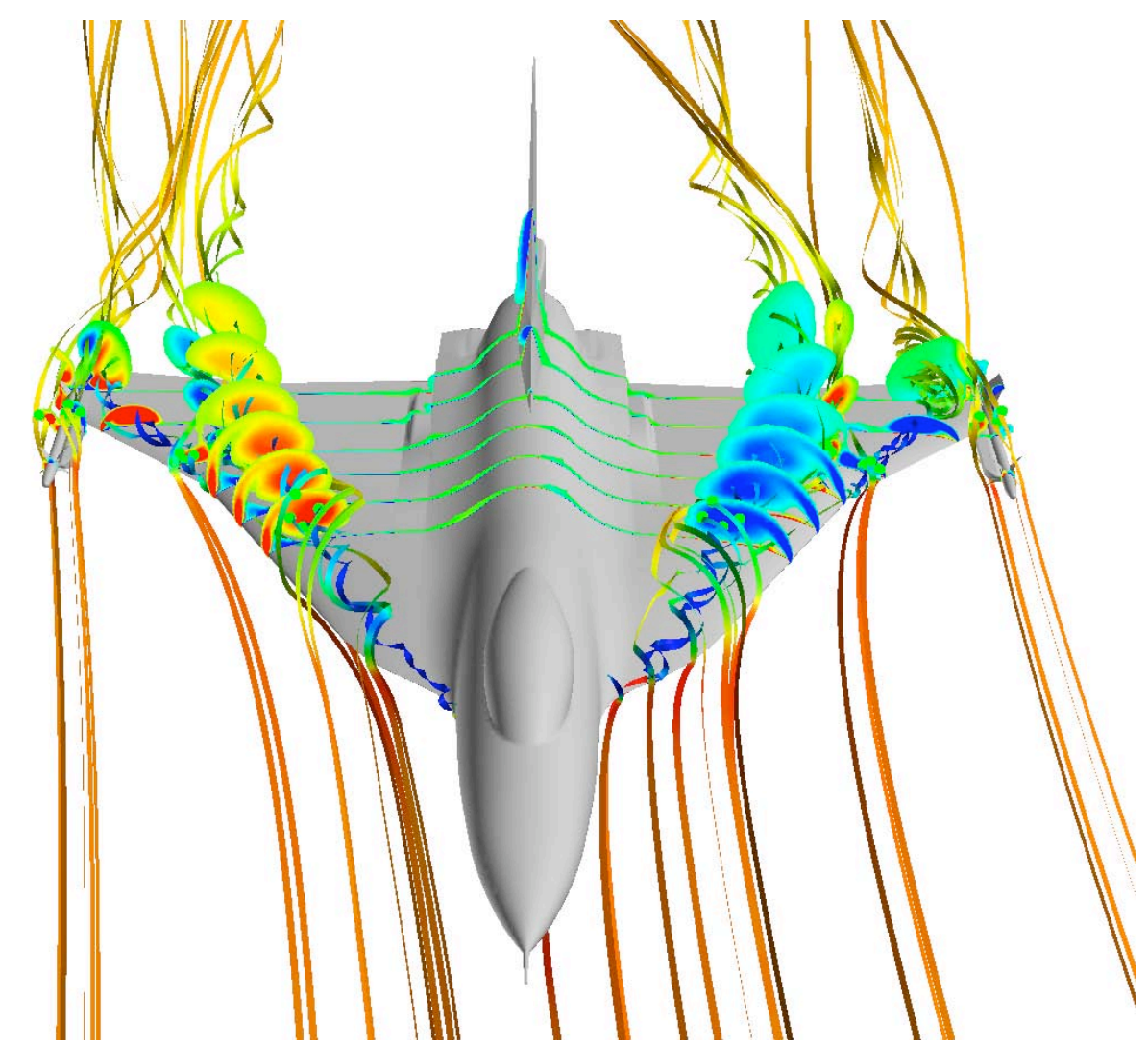

Figure 23. Pressure-colored streamlines and x-vorticity component for FC50 from Karman, et.al. ${ }^{27}$. 
Table 4: Seven Flight Conditions to be Examined

\begin{tabular}{|c|c|c|c|c|}
\hline Flight Condition & Actual Mach No. & $\begin{array}{c}\text { Actual } \boldsymbol{\alpha}, \\
\text { degs }\end{array}$ & $\begin{array}{c}\text { Actual } \boldsymbol{\beta}, \\
\text { degs }\end{array}$ & Actual Reynolds No. \\
\hline FC7 & 0.304 & 11.89 & -0.133 & $44.4 \mathrm{E}+06$ \\
\hline FC19 & 0.36 & 11.85 & +0.612 & $46.8 \mathrm{E}+06$ \\
\hline FC46 & 0.527 & 10.4 & +0.684 & $46.9 \mathrm{E}+06$ \\
\hline FC70 & 0.97 & 4.37 & +0.310 & $88.77 \mathrm{E}+06$ \\
\hline FC25 & 0.242 & 19.84 & 0.725 & $32.22 \mathrm{E}+06$ \\
\hline FC50 & 0.434 & 13.56 & +5.31 & $39.41 \mathrm{E}+06$ \\
\hline FC51 & 0.441 & 12.89 & -4.58 & $38.95 \mathrm{E}+06$ \\
\hline
\end{tabular}

Table 5: Associated Engine Parameters* for these Flight Conditions

\begin{tabular}{|c|c|c|c|c|c|c|c|c|}
\hline $\begin{array}{c}\text { Flight } \\
\text { Condition }\end{array}$ & $\begin{array}{c}\text { Free } \\
\text { Stream } \\
\text { Altitude, } \\
\text { ft }\end{array}$ & $\begin{array}{c}\text { Free } \\
\text { Stream } \\
\text { Mach }\end{array}$ & $\begin{array}{c}\text { Inlet Duct } \\
\text { Exit Static } \\
\text { Temp., degs } \\
\text { R }\end{array}$ & $\begin{array}{c}\text { Inlet Duct } \\
\text { Exit Static } \\
\text { Press., psia }\end{array}$ & $\begin{array}{c}\text { Inlet Duct } \\
\text { Exit } \\
\text { Velocity, } \\
\text { ft/sec }\end{array}$ & $\begin{array}{c}\text { Inlet } \\
\text { Duct } \\
\text { Exit } \\
\text { Mach }\end{array}$ & $\begin{array}{c}\text { Mixing } \\
\text { Plane } \\
\text { Total } \\
\text { Temp., } \\
\text { degs R }\end{array}$ & $\begin{array}{c}\text { Mixing } \\
\text { Plane } \\
\text { Total } \\
\text { Press., } \\
\text { psia }\end{array}$ \\
\hline FC7 & 5000 & 0.304 & 498 & 11 & 379.6 & 0.347 & 1050 \\
\hline FC19 & 10000 & 0.36 & 485.8 & 10.2 & 345.8 & 0.32 & 1050 \\
\hline FC46 & 24000 & 0.527 & 443.6 & 5.85 & 404.3 & 0.39 & 1045 & 14.8 \\
\hline FC70 & 22300 & 0.97 & 519 & 10.65 & 464.7 & 0.416 & 1200 \\
\hline FC25 & 10000 & 0.242 & 470.1 & 8.72 & 474.8 & 0.447 & 1209 \\
\hline FC50 & 24000 & 0.434 & 440 & 5.16 & 483.3 & 0.47 & 1154 \\
\hline FC51 & 24000 & 0.441 & 431.8 & 5.19 & 468.6 & 0.46 & 1146 \\
\hline
\end{tabular}

*The numbers in this table do not represent any particular engine.

\section{Concluding Remarks}

A- $\quad$ Aircraft companies, government laboratories, and universities have access to database sets that may include flight data, but many of these sets are considered proprietary and are only used by them to assess and improve their codes. They hold this information in a closed environment so as to maintain a competitive advantage. The CAWAP dataset, being open, allowed researchers in these organizations to predict flight data in a cooperative manner under the RTO "umbrella" and facilitate doctoral studies. 
B- There is interest in the international aeronautical community (airframe companies, government laboratories and universities) in being able to predict the flow physics measured on a fighter aircraft.

C- $\quad$ An international team of experts can be assembled with enough patience and institutional support when there is a focused common problem of mutual interest that can provide positive payoff for each organization.

D- $\quad$ The efforts expended by the participating organizations/researchers described here have led to the development of best practices for their flow solvers for the F-16XL aircraft. Moreover, an improvement in the ability (Technology Readiness Level) of organizations/researchers to predict complete fighter aircraft flow physics at real flight conditions has occurred, in part, due to their participating in this shared and open environment.

\section{Summary}

This paper has traced the F-16XL-1 aircraft and the flight flow-physics data from a NASA- only activity to encompass others in the NATO community interested in predicting these data. The Cranked Arrow Wing Aerodynamics Project (CAWAP) has been internationalized under the auspices of the scientific arm of NATO and the Technology Readiness Level of computational tools has been increased. Sample results obtained by CAWAPI facet members have been highlighted to show the breadth of work to be presented by them in their own papers.

\section{Acknowledgments}

The CAWAPI facet gratefully acknowledges the support provided by Lockheed Martin Aeronautics Company - Fort Worth in providing a refined iges geometry file and the parameter values of a generic engine that were subsequently used by facet members in their CFD studies, and the geometrical work performed by Mr. Edward B. Parlette of Vigyan, Inc. in generating a series of unstructured, tetrahedral grids from the iges file, with the last one known as the base grid.

\section{References}

${ }^{1}$ Bertin, John J.; and Smith, Michael L.: Aerodynamics for Engineers, Second ed. Prentice-Hall, Inc., 1989, p 146.

${ }^{2}$ Lamar, John E., Obara, Clifford J.; Fisher, Bruce D.; and Fisher, David F.: Flight, Wind-Tunnel, and Computational Fluid Dynamics Comparison for Cranked Arrow Wing (F-16XL-1) at Subsonic and Transonic Speeds. NASA/TP-2001-210629, February 2001.

${ }^{3}$ Hillaker, H.J.: F-16XL Flight Test Program Overview. AIAA Paper 83-2730, November 1983.

${ }^{4}$ Bower, J. N.; and Scott, S. R.: The F-16XL Flight Test Program. Soc. of Flight Test Engrs. $15^{\text {th }}$ Ann. Symp. Procs., Aug. 1984, pp. 9-1 to 9-5.

${ }^{5}$ Talty, P.K.; and Caughlin, D.J.: F-16XL Demonstrates New Capabilities in Flight Test at Edwards Air Force Base. J. Aircraft, Vol.25, No.3, March 1988, pp.206 to 215.

${ }^{6}$ Bertelrud, A.: Total Head/Static Measurements of Skin Friction and Surface Pressure. AIAA Journal, Vol. 15, No. 3, Mar. 1977, pp. 436-438.

${ }^{7}$ Thomas, J. L., Anderson, W. K.; and Krist, S. T.: Navier-Stokes Computations of Vortical Flows over Low-Aspect-Ratio Wings. AIAA Journal, Vol. 28, No. 2, Feb. 1990, pp. 205-212.

${ }^{8}$ Thomas, J. L.; Weston, R. P.; Luckring, J. M.; Walters, R. W.; Reu, T.; and Ghaffari, F.: A Patch-Grid Algorithm for Complex Configurations Directed Towards the F-18 Aircraft. AIAA Paper 89-0121, 1989. 
${ }^{9}$ Spellman, M. W.: Model and Test Information Report 1/9-Scale F-16E Force and Loads Model. Rep. no. 400PR026, General Dynamics Corp., Aug. 1981.

${ }^{10}$ Elbers, W. K.: Wind Tunnel Data Report 1/9-Scale F-16E Pressure Model NASA Ames Research Center Tests 517-1-11 and 517-1-97. Rep. no. 400PR037, Vol. II, General Dynamics Corp., Dec. 1981.

${ }^{11}$ Hahne, David E.: Low-Speed Aerodynamic Data for an 0.18-Scale Model of an F-16XL With Various Leading-Edge Modifications. NASA/TM-1999-209703, 1999.

${ }^{12}$ Lessard, Wendy B.: Subsonic Analysis of 0.04-Scaled F-16XL Models Using an Unstructured Euler Code. NASA TP-3597, 1996.

${ }^{13}$ White, Frank M.: Viscous Fluid Flow. McGraw-Hill Inc., pp. 474-476, 1974.

${ }^{14}$ Lamar, John E.: Cranked Arrow Wing (F-16XL-1) Flight Flow Physics with CFD Predictions at Subsonic and Transonic Speeds. Presented at RTO AVT Symposium on Advanced Flow Management; Part A - Vortex Flow and High Angle of Attack, Paper Number 44, in Loen Norway during May 7-11, 2001.

${ }^{15}$ Hummel, D. and Redeker, G.: A new vortex flow experiment for computer code validation. Presented at RTO AVT Symposium on Advanced Flow Management; Part A - Vortex Flow and High Angle of Attack, Paper Number 8, in Loen Norway during May 7-11, 2001.

${ }^{16}$ Lamar, John E.; Conin, Catherine K.; and Scott, Laura E.: A Review of Steps Taken to Create an International Virtual Laboratory at NASA Langley for Aerodynamic Prediction and Comparison. Prog Aerospace Sci, Vol. 40, p.163-172, 2004.

${ }^{17}$ Lamar, John E.; Cronin, Catherine K.; and Scott, Laura E.: Virtual Laboratory Enabling Collaborative Research in Applied Vehicle Technologies. In AVT-123 Symposium on "Flow Induced Unsteady Loads and The Impact on Military Applications”, Keynote 2, Budapest, Hungary, April 25-29, 2005.

${ }^{18}$ Boelens, O.J.; Goertz, S.; Morton, S.A.; Fritz, W.; and Lamar, J.E.: Description of the F-16XL Geometry and Computational Grids Used in CAWAPI. AIAA Paper 2007-0488, To be presented at 45 ${ }^{\text {th }}$ AIAA Aerospace Sciences Meeting and Exhibit, Reno NV, January 8-11, 2007.

${ }^{19}$ Boelens, O.J.; Spekreijse, S.P.; Sytsma, H.A.; and de Cock, K.M.J.: Comparison of measured and simulated flow features for the full-scale F-16XL aircraft. AIAA Paper 2007-0489, To be presented at 45 ${ }^{\text {th }}$ AIAA Aerospace Sciences Meeting and Exhibit, Reno NV, January 8-11, 2007.

${ }^{20}$ Badcock, K.J.: Evaluation of Results from a Reynolds Averaged Multiblock Code Against F-16XL Flight Data. AIAA Paper 2007-0490, To be presented at $45^{\text {th }}$ AIAA Aerospace Sciences Meeting and Exhibit, Reno NV, January 8-11, 2007.

${ }^{21}$ Elmiligue, A.A.; Abdol-Hamid, K.S.; and Massey, S.J.: PAB3D Simulations for the CAWAPI F-16XL. AIAA Paper 2007-0491, To be presented at $45^{\text {th }}$ AIAA Aerospace Sciences Meeting and Exhibit, Reno NV, January 8-11, 2007.

${ }^{22}$ Fritz, W.: Hybrid Grid RANS Solutions For The CAWAPI F-16XL. AIAA Paper 2007-0492, To be presented at $45^{\text {th }}$ AIAA Aerospace Sciences Meeting and Exhibit, Reno NV, January 8-11, 2007.

${ }^{23}$ Morton. S.A.; McDaniels, D.R.; and Cummings, R.M.: F-16XL Unsteady Simulations for the CAWAPI Facet of RTO Task Group AVT-113. AIAA Paper 2007-0493, To be presented at $45^{\text {th }}$ AIAA Aerospace Sciences Meeting and Exhibit, Reno NV, January 8-11, 2007.

${ }^{24}$ Goertz, S. and Jirasek, A.: Unstructured Steady/Unsteady Solutions with Edge for CAWAPI F-16XL at KTH/FOI. AIAA Paper 2007-0678, To be presented at $45^{\text {th }}$ AIAA Aerospace Sciences Meeting and Exhibit, Reno NV, January 8-11, 2007. 
${ }^{25}$ Michal, T.; Oser, M.; Mani, M.; and Roos, F.: BCFD Unstructured-Grid Predictions On The F-16XL (CAWAPI) Aircraft. AIAA Paper 2007-0679, To be presented at $45^{\text {th }}$ AIAA Aerospace Sciences Meeting and Exhibit, Reno NV, January 8-11, 2007.

${ }^{26}$ Davis, M.B.; Reed, C.; and Yagle, P.: Hybrid Grid Solutions on the (CAWAPI) F-16XL Using Falcon v4. AIAA Paper 2007-0680, To be presented at $45^{\text {th }}$ AIAA Aerospace Sciences Meeting and Exhibit, Reno NV, January 8-11, 2007.

${ }^{27}$ Karman, S.; Mitchell, B.; and Sawyer, S.: Unstructured Grid Solutions of CAWAPI F-16XL by UT SimCenter. AIAA Paper 2007-0681, To be presented at $45^{\text {th }}$ AIAA Aerospace Sciences Meeting and Exhibit, Reno NV, January 8-11, 2007.

${ }^{28}$ Lamar, J.E. and Abdol-Hamid, K.S.: USM3D Unstructured Grid Solutions for CAWAPI at NASA LaRC. AIAA Paper 2007-0682, To be presented at $45^{\text {th }}$ AIAA Aerospace Sciences Meeting and Exhibit, Reno NV, January 8-11, 2007.

${ }^{29}$ Rizzi, A.; Badcock, K.: Jirasek, A.; and Boelens, O.: What Was Learned from Numerical Simulations of F-16XL (CAWAPI) at Flight Conditions. AIAA Paper 2007-0683, To be presented at $45^{\text {th }}$ AIAA Aerospace Sciences Meeting and Exhibit, Reno NV, January 8-11, 2007. 